\title{
Perioperative Cardiovascular Evaluation of Patients Oxygen Balance and Tissue Metabolic Score (TMS)
}

\author{
Avraham Mayevsky*, Michael Tolmasov and Mira Mandelbaum \\ The Mina \& Everard Goodman Faculty of Life Sciences, Bar-Ilan University, Ramat-Gan 5290092, Israel
}

Received: June 15, 2018; Accepted: July 16, 2018; Published: July 18, 2018

*Corresponding author: Avraham Mayevsky, Professor Emeritus, Faculty of Life Sciences, The Mina \& Everard Goodman Faculty of Life Sciences, Bar-Ilan University, Ramat-Gan 5290002, Israel; Tel: 972-544-861854; Fax: 972-3-5351561; E-mail: mayevskya@gmail.com

\begin{abstract}
During the perioperative period of cardiovascular surgeries an imbalance between oxygen supply and demand may lead to postoperative cognitive decline that may affect about $20 \%$ of the operated patients. In order to minimize the development of brain damage, few companies had developed monitoring devices that could provide real-time information regarding brain oxygenation, brain electrical activities or cerebral blood flow. Nevertheless this approach is not the appropriate way to detect an early warning signal that may serve as an indicator of brain negative oxygen balance. The alternative approach is to monitor tissue oxygen balance of one of the less vital organ in the body that may serve as an early warning signal of deterioration of body oxygen balance. In this review, the use of a multiparametric monitoring device (CritiView) connected to the patient's urethral wall via a 3-way Foley catheter that measure in real time 4 parameters representing tissue oxygen balance. Mitochondrial NADH is measured by surface fluorometry/reflectometry. In addition, tissue microcirculatory blood flow, tissue reflectance and hemoglobin oxygenation are measured as well. The measured 4 parameters could be integrated together with systemic hemodynamic parameters to provide in real time a new Tissue Metabolic Score (TMS). The device was tested both in vitro and in vivo in a small animal model and in preliminary clinical trials in patients undergoing vascular or open heart surgery. In patients, the monitoring started immediately after the insertion of a 3-way Foley catheter (urine collection) to the patient and was stopped when the patient was discharged from the operation room. The results show that monitoring the Urethral wall oxygen balance provides information in correlation to the surgical procedure performed.
\end{abstract}

Keywords: Patient Monitoring; Mitochondrial Function; NADH Redox State; Microcirculatory Blood Flow; Hemoglobin Oxygenation;

\section{Introduction}

All major surgeries of patients performed under general anesthesia, require monitoring of vital functions performed by the cardiovascular and the respiratory systems. It is very important to monitor the vital signs such as ECG, heart rate, blood pressure, respiration and oxygen saturation of the blood. In the last 25 years new parameters were added to the monitoring systems of patients including stroke volume, cardiac output, depth of anesthesia and cerebral and tissue oxygenation [1]. In spite of the intensive monitoring options during the perioperative period, brain injury is a major cause of patient's morbidity after cardiac surgery as discussed in many publications [2-6]. They showed that the consequences are, higher operative mortality, prolongation of hospitalization periods, and decrease in quality of life. Grogan et al. [7] reviewed the published material and provided evidenced based recommendations to improve brain protection during cardiac surgery including CPB (Cardio Pulmonary Bypass). It seems that the current monitoring tools are not providing an alarming signal that will enable to minimize the effect of the surgery on brain function during the perioperative stage. In 2002, Edmonds [8] discussed the option of neurophysiological monitoring during heart surgery. A recent published review by Ekbal et al. [9] summarizes the additional monitoring tools that may provide, in real time, early warning signals on tissue perfusion and metabolism in critically ill patients. In 2016, Scheeren [10] presented a list of new technologies that will enable the clinician to monitor and evaluate the microcirculation and tissue oxygenation in addition to the macro-circulation and respiratory function available today.

In the present review I will describe in details a new multiparametric monitoring approach that provide in real time critical information that could serve as an early warning signals for the changes in tissue oxygen balance during cardiovascular surgeries.

\section{Tissue Energy Metabolism}

The functional capacity of any tissue is related to its ability to perform its work. It is possible to assess this ability through the knowledge of changes in the oxygen balance, i.e. the ratio of oxygen supply to oxygen demand in the tissue. According to our long term experience; the "holy grail" of patients' monitoring at the various physiological compartments is to keep positive tissue oxygen balance ensuring optimal mitochondrial function. Schematic presentation of the balance between oxygen supply and demand in a typical tissue is shown in Figure 1A. The supply of oxygen is dependent upon microcirculatory blood flow (TBF), blood volume (TBV) and the level of oxygen bound to the hemoglobin $\left(\mathrm{HbO}_{2}\right)$ in the small blood vessels, namely, in the microcirculation [11]. The level of oxygenated hemoglobin in the microcirculation is affected by two factors, namely, oxygen consumption by the mitochondria and the microcirculatory blood flow. The demand for oxygen is affected by the specific activities taking place in each organ. The intracellular level of mitochondrial NADH (the reduced form) is a parameter related to oxygen balance $[12,13]$.

It is now more than 60 years since the significant work of 
A

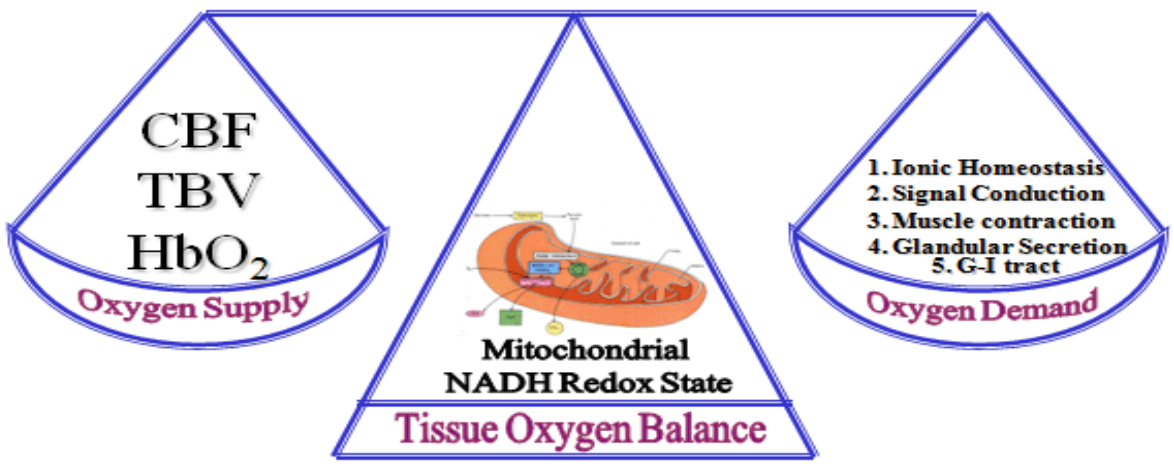

B

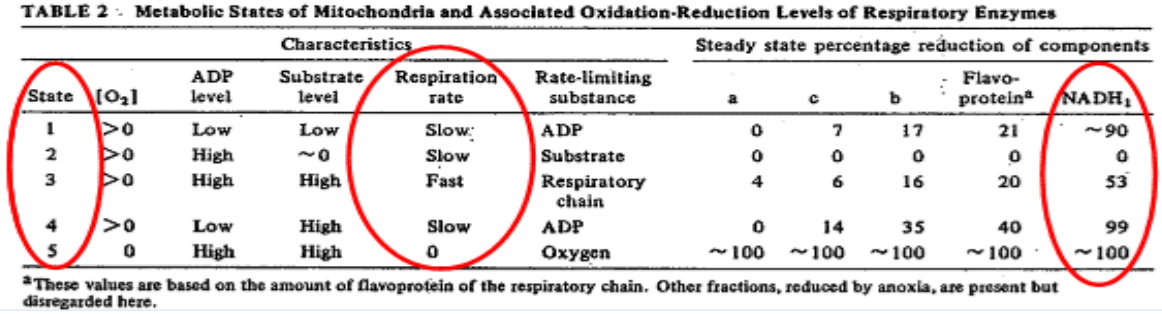

Figure 1A: Schematic presentation of tissue oxygen balance evaluated by energy supply and demand. Energy supply could be measured by monitoring tissue blood flow (TBF), tissue blood volume (TBV) and hemoglobin oxygenation $\left(\mathrm{HbO}_{2}\right)$ which is similar in all tissues. Energy demand varies between the different tissues and may include Ionic Homeostasis, Signal Conduction, Muscle contraction, Glandular Secretion and G-I tract and kidney function. Mitochondrial NADH redox state serve as an indicator for tissue energy or oxygen balance

Figure 1B: The definition of mitochondrial metabolic state, in vitro, in 1955, by Chance and Williams, opened up a new era in spectroscopic measurements of respiratory chain enzyme's redox state in vitro as well as in vivo.

Chance \& Williams on mitochondrial metabolic state in vitro as summarized in Figure 1B, was published [14].

The discovery of the pyridine nucleotides was made by Harden \& Young about 110 years ago $[15,16]$ and was followed by the description of its full structure by Warburg and collaborators 30 years later [17]. All those historical studies led to the first detailed experiments, by Chance et al. [18], in which $\mathrm{NADH}$ (Nicotine amide adenine dinucleotide) fluorescence, was used as a marker of mitochondrial function of the brain and kidney in vivo in the anesthetized animals.

Figure 2 shows the gradient of oxygen between room air through the lungs, the large arteries and small arterioles to the intracellular space and finally the mitochondrion [19]. In this scheme the various points of patients' monitoring are presented. As can see, the last usual parameter, in the oxygen gradient, is the pulse oximeter that measures the saturation of hemoglobin in the arteries that have a pulse. As of today, monitoring of the microcirculation and especially mitochondrial function is not a standard approach and a Figure 3 part D presents the involvement of the mitochondria in cellular and tissue energy metabolism. Substrates and $\mathrm{O}_{2}$ are supplied and regulated by the blood in the microcirculation, namely from the very small arterioles and the capillary bed. The main function of the mitochondria is to convert the potential energy stored in various substrates and its metabolites (e.g., glucose) into ATP. The inner membrane of the mitochondria contains five complexes of integral membrane proteins, including NADH dehydrogenase (Complex 1). Three of those proteins are involved in the respiratory chain activity. The main function of the respiratory chain is to gradually transfer electrons from NADH and FADH2 (originating from the Krebs cycle) to oxygen $\left(\mathrm{O}_{2}\right)$. With the addition of protons $(\mathrm{H}+)$, water molecules (H2O) are generated in Complex 4. NADH is a substrate or a coenzyme for the enzymatic activity of dehydrogenases that form part of the respiratory chain and reside in the inner membrane of the mitochondria.

The formation of ATP depends on the sufficiency of substrate (i.e. glucose) and oxygen supply to the tissue by the blood flow and hemoglobin oxygenation in the microcirculation (Fig. 3) as well as on the integrity of mitochondrial activity. Without the sufficient supply of ATP, cells cannot function properly and can ultimately die. Since most of the energy consumed by tissues is dependent upon the availability of oxygen, under normal mitochondrial function, there is high coupling between oxygen supply and energy production. When mitochondrial activity is damaged, due to various reasons, this coupling is disrupted.

The electron transfer (oxidation/reduction) down the respiratory chain results in the production of adenosine triphosphate (ATP). Concomitantly with the electron transport, the respiratory chain components switch between reduced and oxidized states, each of which has different spectroscopic properties [14]. Hydrolysis of the pyrophosphate bonds provides the energy necessary for the cell's work. In order to assess the energy demand, it is necessary to measure different organ-specific parameters. For example, in the brain, the energy demand can be evaluated by measuring the extracellular levels of $\mathrm{K}+$ that reflect the activity of the major ATP consumer $-\mathrm{Na}+/ \mathrm{K}+\mathrm{ATP}$ 'ase $[12,20]$. In the heart, most of the energy is consumed by muscle contraction activity. On the other hand, the energy supply mechanism is the same for all tissues: oxygenated blood reaching the capillary bed 


\section{Oxygen Gradients from AIR to Mitochondria}

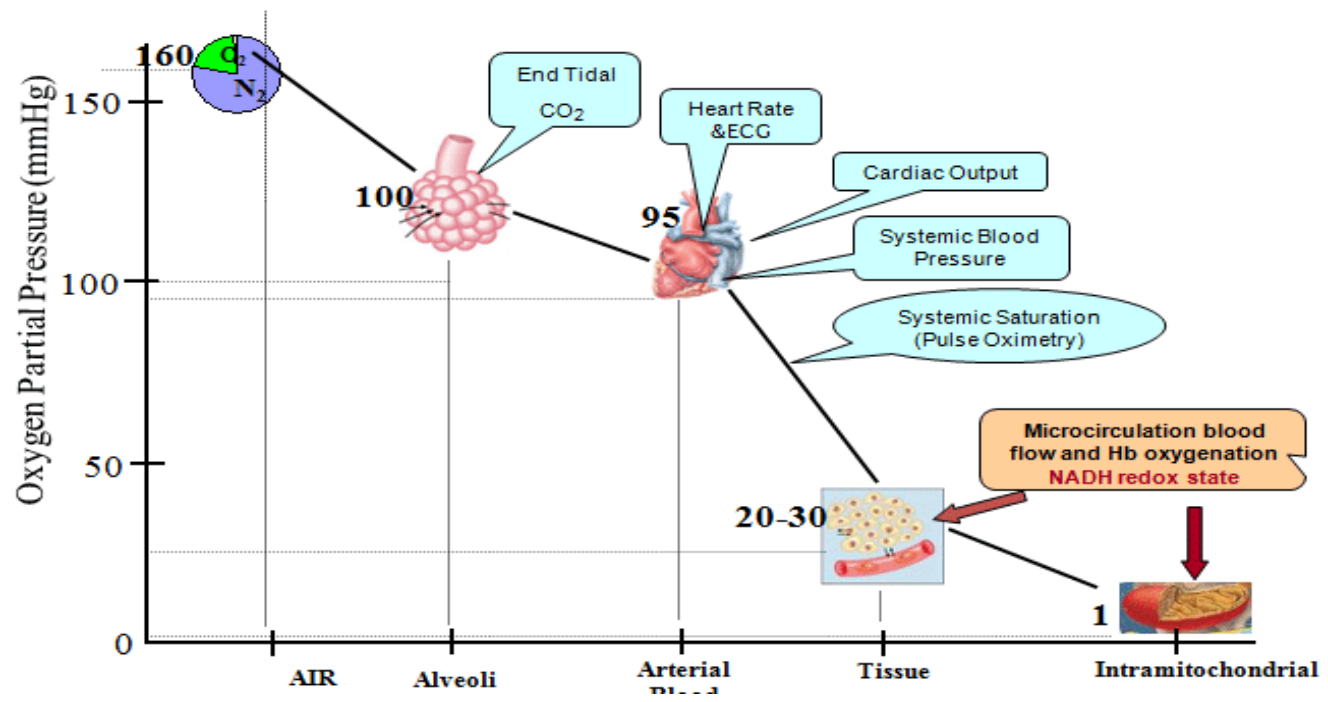

Figure 2: Oxygen gradient from air to the mitochondria. Clinical monitoring of patients includes the various parameters along the oxygen gradient.

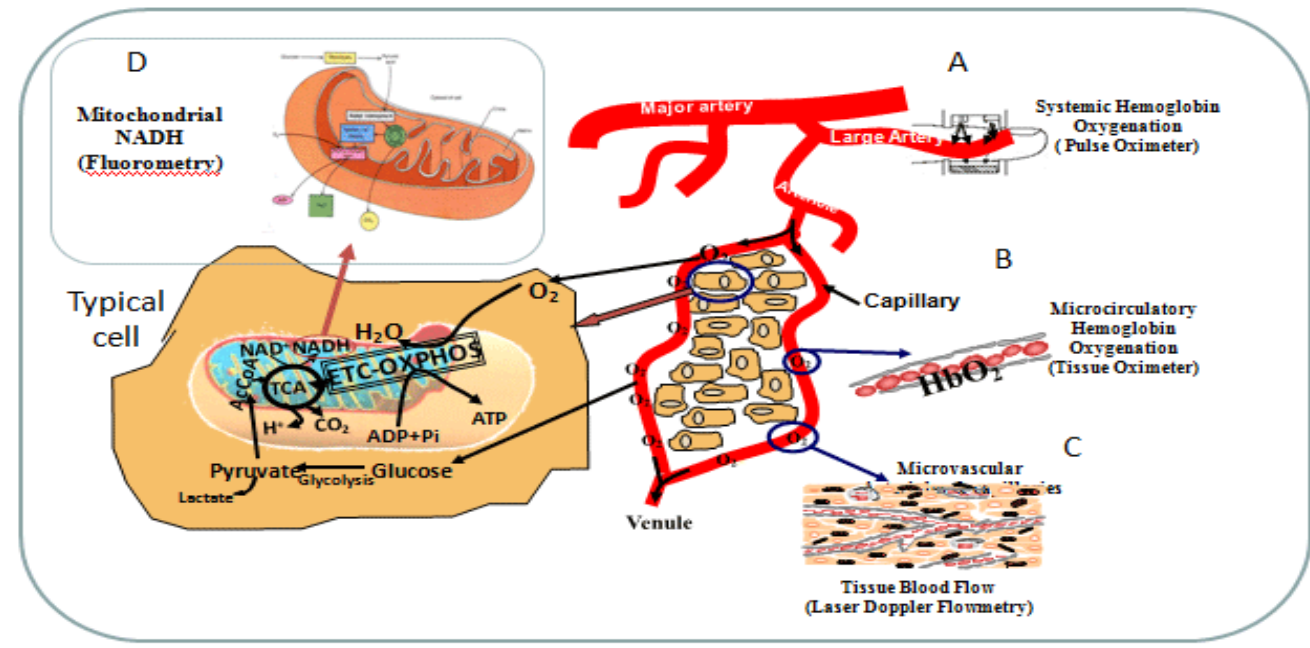

Figure 3: The available techniques for real-time monitoring of energy metabolism at the tissue level. Part A shows the coupling between the macrocirculation monitored by the Pulse oximeter and the microcirculation. B-D monitoring of cellular and intracellular compartments.

releases $\mathrm{O}_{2}$ that diffuses into the cells. Therefore, it is possible to evaluate tissue energy supply by monitoring the following four parameters in all tissues: tissue blood flow (TBF), tissue blood volume (TBV), tissue oxyhemoglobin $\left(\mathrm{HbO}_{2}\right)$ and mitochondrial NADH redox state (See Fig. 3).

The production of available energy (ATP) depends on $\mathrm{pO}_{2}$ (partial oxygen pressure) in the various compartment of the tissue. Information regarding $\mathrm{pO}_{2}$ in the tissue, therefore, is helpful for the evaluation of tissue metabolic activity. Oxygen levels can be measured by oxygen electrodes; however, the information collected is an average of the compartments around the electrode. In the past, the sensitivity and accuracy of oxygen electrodes in the range of $1 \mathrm{mmHg}$ (intracellular level) was not sufficient for the evaluation of mitochondrial function.
The need for an intracellular $\mathrm{pO}_{2}$ indicator, as a physiological and biochemical parameter of living tissue, has emerged more than 50 years ago. Mitochondria are the intracellular organelles that consume most of the oxygen. Therefore, the redox state of electron carriers in isolated mitochondria in vitro as well as in vivo as a function of oxygen concentration has been extensively studied. Chance et al. [19] concluded that "For a system at equilibrium, NADH is at the extreme low potential end of the chain, and this may be the oxygen indicator of choice in mitochondria and tissue as well". Lubbers in 1995 concluded that "the most important intrinsic luminescence indicator is NADH, an enzyme of which the reaction is connected with tissue respiration and energy metabolism" [21].

As of today, the ability to measure tissue energy metabolism at the microcirculation and cellular level is not available for clinical 
applications although preliminary studies were performed recently by our group [22].

\section{Real-time Monitoring of Tissue Oxygen Balance}

Several real-time invasive and noninvasive techniques have been developed to determine tissue energy metabolism or tissue oxygen balance in vivo. A short description of the techniques for monitoring tissue oxygen balance shown in Figure 4 is presented. These techniques could be adapt and use in experimental animals as well as in patients.

A

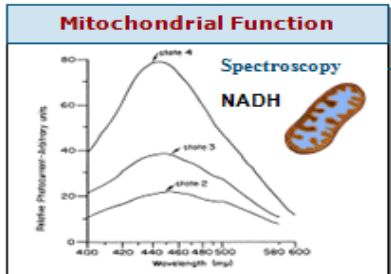

$B$
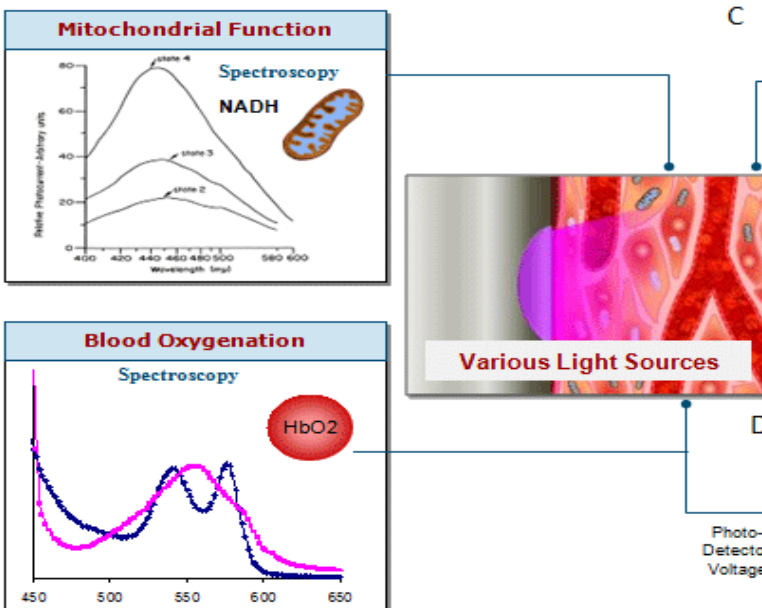

Tissue Blood Flow
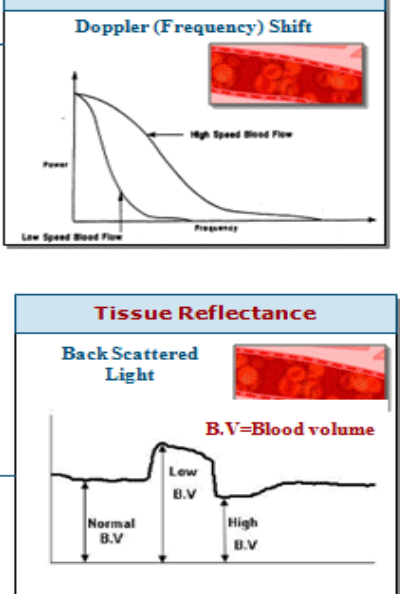

Figure 4: The principles of tissue spectroscopy in order to evaluate tissue viability by the Criti View. Three of the parameters are monitored from the intravascular compartment while the NADH parameter represents the function of the intramitochondrial space.

\section{Mitochondrial NADH (A)}

The discovery of the optical properties of reduced Nicotineamide Adenine Dinucleotide - NADH (earlier names: DPNH - diphosphopyridine nucleotide, or PN - pyridine nucleotide), has led to a very intensive research since the early 1950 's. Only the reduced form of this molecule, NADH, (Figure 5A and B) [23], absorbs light at 320-380 nm (Fig. 5C) and emits fluorescent light at 420-480 $\mathrm{nm}$ range (Fig. 5 D) [24]
NADH monitoring from the organ surface (brain, kidney, liver, testis, etc.) is performed by the fluorometric technique based on the original work by Chance and Williams [14]. The excitation light (366 nm) is passed from the fluorometer to the tissue through a bundle of quartz optical fibers. The emitted light $(450 \mathrm{~nm})$, together with the reflected light at the excitation wavelength, is transferred to the fluorometer through another bundle of fibers. The measured changes in fluorescence (A) and reflectance (D)
A.

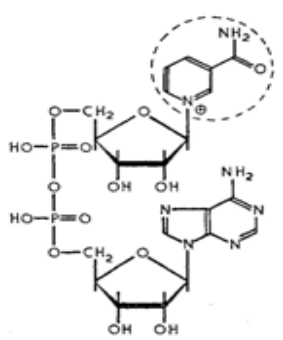

NAD - nicotinamide adenine dinucleotide

c.

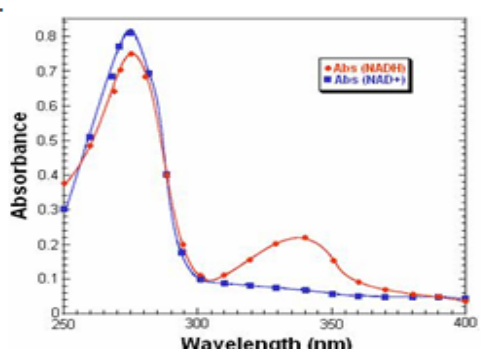

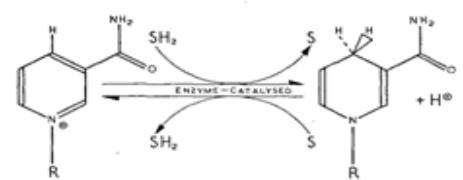

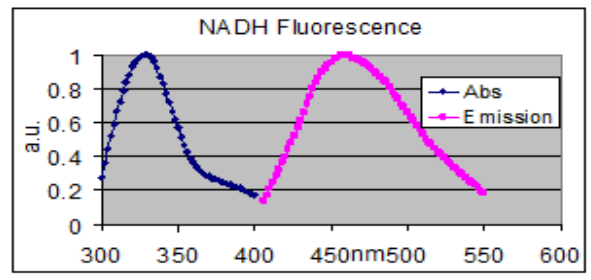

Figure 5: A. The structures of NAD+. The nicotinamide group (broken ring) is the "functional" part of both molecules i.e. the portion of the molecules where oxidation and reduction take place and B. The transition between oxidized and reduced NADH. C. Absorption Spectra of NAD+ and NADH. D. Excitation and emission spectra of NADH. 
signals are calculated as percent values relative to the calibrated signals under normoxic conditions. This type of calibration is not absolute, but it provides reliable and reproducible results for different animals and different laboratories [12, 20]. The combination of NADH fluorescence and LDF techniques has been routinely utilized in our laboratory for the past 20 years [25-28].

\section{Microcirculatory $\mathrm{Hb}$ Oxygenation (B)}

Oxygenated hemoglobin can be monitored at the microcirculatory level using the absorption spectrum of hemoglobin, which is different in its oxygenated or deoxygenated state. One possibility is to illuminate the tissue with $585 \mathrm{~nm}$ light which is an isosbestic point, and with $577 \mathrm{~nm}$ light, which is a non-isosbestic point, in which the oxy-hemoglobin absorb more light than the deoxy-hemoglobin form. By subtracting the $585 \mathrm{~nm}$ reflectance from the $577 \mathrm{~nm}$ reflectance, a parameter correlated to blood oxygenation is obtained. A detector collects the light reflected from the tissue and converts it into oxy-hemoglobin levels $[29,30]$.

\section{Microcirculatory Blood Flow (C)}

Real-time monitoring of tissue blood flow (TBF) can be achieved using laser Doppler flowmetry (LDF) [31-33]. The LDF measures relative changes, which correlate with the relative TBF alterations. The principle of LDF is to measure the Doppler shift, namely, the frequency change undergone by the light reflected from moving red blood cells. The results are presented as percentages of a full scale $(0 \%-100 \%)$, providing relative perfusion values. In our laboratory, we used LDF to measure TBF (tissue blood flow) in the brain, kidney, and liver [25, 34, 35]. This method has been successfully employed in many animal models, including rodents, cats and baboons under stroke [13].

\section{Monitoring the Heart in an Animal Model}

In 1959, Chance and Jobsis [36] applied the newly developed NADH fluorometric method to frog sartorius muscle in vitro and found a decrease in NADH due to a series of twitches leading to an increased ATP breakdown into ADP. Chance [37] applied the same approach to monitor the toad sartorius muscle in vivo and found a clear NADH oxidation depending on the rate of stimulation. Additional studies described the NADH changes in the heart in various animal models [38-42].

The dog is the best animal model to study NADH in real time by fiber optic based fluorometry reflectometry. The technique was developed by Kedem and Mayevsky [43] in the early 1980s. Transient anoxia reversibly increased NADH levels. Increased heart rate also increased NADH levels followed by an increase in coronary blood flow, indicating a change in $\mathrm{O}_{2}$ balance. In the next study the effect of heart rate on NADH redox state was tested [44]. An increase in heart rate above $150 \mathrm{bpm}$ under normal conditions increased NADH level, while this was not seen under hypopnea. NADH was monitored in a local region of the myocardial surface in dogs. We have developed the technique to monitor the NADH in cardiac muscle in the beating heart of dogs [43]. In the dog heart we sutured the light guide holder (three points) to the muscle few millimeters from the monitoring site as can be seen in Figure 6A and B. This enabled the heart to behave normally while the probe was moving together with the muscle and stable

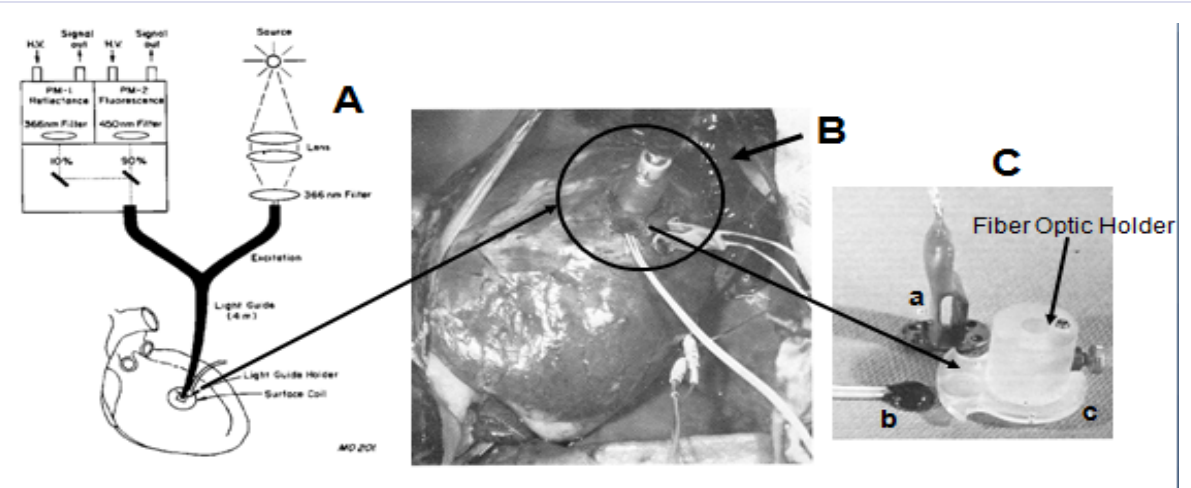

D

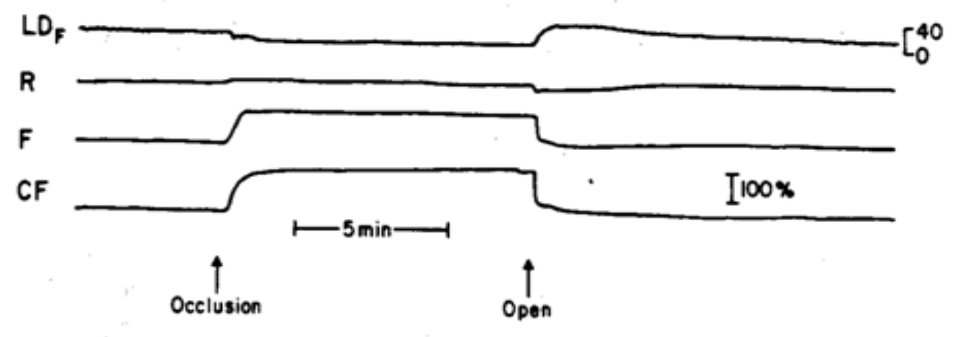

Figure 6: A- Schematic drawing of the system used for measuring local blood flow, NADH fluorescence and tissue reflectance from the surface of the myocardium. B-Photograph of the measuring system located on the beating heart in situ. C - Sutured on the apex of the left ventricle is the cannula supporting the fiber optic light guide and the thermistor at its base, as well as the miniature strain gauge arch to the right of the light guide holder. D- Response of heart to ischemia/reperfusion. Note that during ischemia, LDf decreased and CF increased. These changes were reversed upon reperfusion. Also note the initial hyperemic response upon reperfusion, as monitored by LDf = percentage change from baseline in tissue flow measured by the laser Doppler flow (LDF) system; R : rflectance measured by the NADH fluorometer; F = fluorescence (uncorrected) measured by the NADH fluorometer; $\mathrm{CF}$ = corrected fluorescence (R-F) reported as percentage change from baseline; 
signals were recorded. This arrangement enabled us to connect other probes and measure local blood flow and contractility of the heart muscle (Figure 6C).

A typical response of the heart to local ischemia is presented in Figure 6D [45]. Ischemia was induced by occlusion of a balloon placed around the LAD. Microcirculatory blood flow (LDF) decreased and NADH increased immediately after the occlusion of the LAD and remained stable until the reperfusion of the heart as expected.

\section{Cardiovascular Surgeries and Body Oxygen Homeostasis in Patients}

In order to keep body oxygen homeostasis during various surgeries or in the various operation rooms, the clinicians are using various devices that measure various compartment or various organs. One approach, in monitoring patients, is to measure one or more parameters in a specific organ and the information accumulated represents the events occurring in the organ itself. For example, monitoring the intra cranial pressure (ICP) or the Electroencephalography (EEG) in neurosurgical patients will provide information on the events developed in the brain itself [46]. The information is dependent initially upon local pathological events occurred in the brain. Monitoring the Electrocardiography (ECG) represents the electrical activity of the heart and most of the changes are correlated to local and not systemic events initially.

The second approach in monitoring patients is to measure one or more parameters in one location in the body and the results are representing one or more physiological systems in the body. There are a group of parameters that are measured routinely from the cardiovascular and respiratory system. It provides information on systemic events such as changes in gas exchange in the respiratory system or cardiac output affecting the perfusion of various organs in the body. The second group of parameters could be measured at the tissue level and the accumulated results represent the oxygen balance of the entire body.

The pattern of pathophysiological cascade of events that may occur in many emergency clinical situations in adult patients and may lead to morbidity and mortality is shown in Figure 7. For example, during cardiovascular surgeries the stressful situation may lead to metabolic disturbances and may end up in cellular energy derangement [47-50]. All patients undergoing sever operations such as cardiac bypass, neurosurgical or organ transplantation may develop the Body Emergency Metabolic State- BEMS. Other patients that may develop the BEMS are newborns during delivery or elderly patients treated in the internal medicine departments. As a central protection mechanism, blood flow redistribution will occur and the three protected organs (brain, heart and adrenal gland) will receive more blood and $\mathrm{O}_{2}$, while the peripheral organs or areas (skin and muscles), as well as others less vital visceral organs, will undergo vasoconstriction and a decrease in blood flow and $\mathrm{O}_{2}$ supply will occur. Monitoring at the cellular function is the most significant indicator of the metabolic state of patients in critical care medicine $[9,51]$.

The energy balance in the most vital organs will remain positive due to higher blood flow while the less vital organs will be hypo perfused and a negative energy balance will developed. As presented in Figure 7, the blood flow redistribution mechanism will affect the energy production by the mitochondria in the most vital and less vital organs in the body. This change in mitochondrial function will affect the production of ATP.

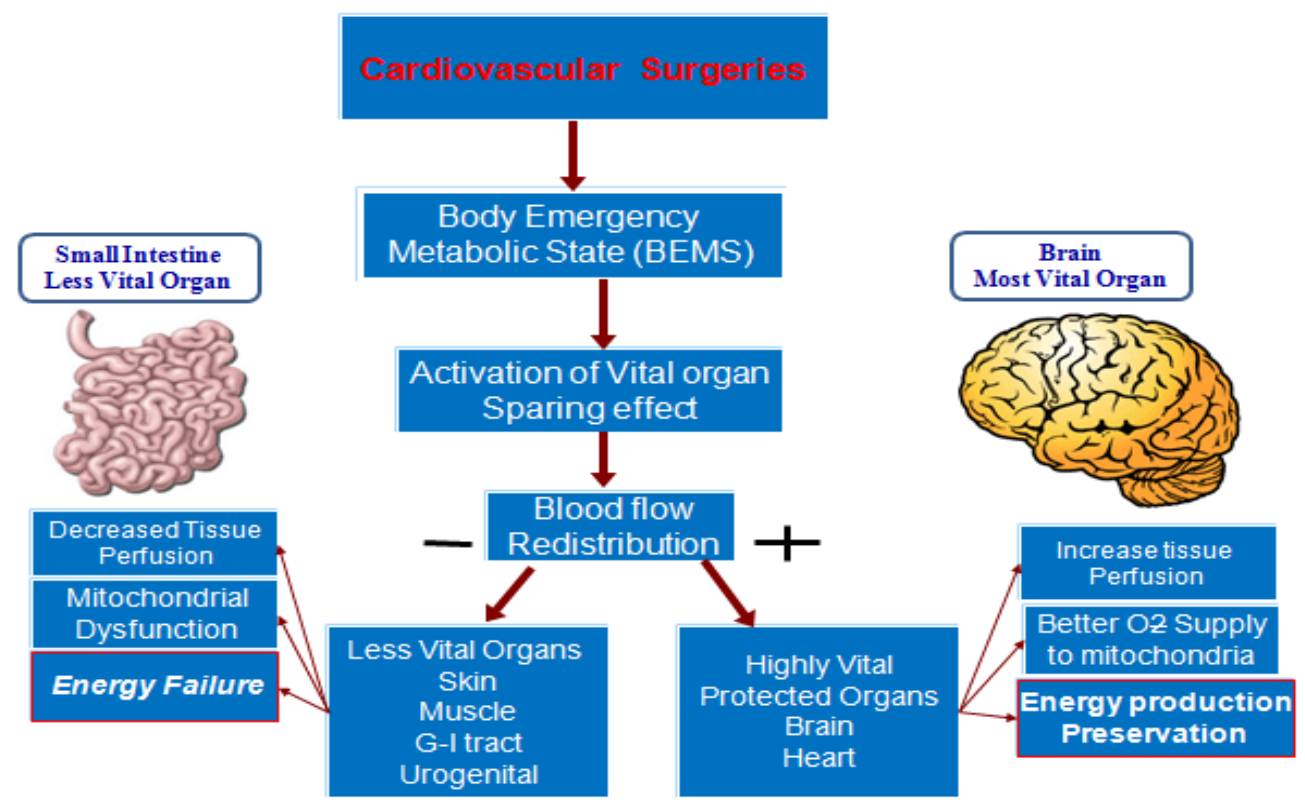

Figure 7: Schematic presentation of the events developed under a surgical procedure which leads to the development of body emergency metabolic state (BEMS). As a result, blood flow redistribution will lead to an increase in blood flow to the most vital organs (brain) and a decrease in blood flow to the less vital organs (small Intestine). 
In order to test the hypothesis named "blood flow redistribution" under body emergency metabolic state, we performed animal studies mimicking the possible clinical situations.

The multisite multiparametric monitoring system (MSMP) monitors both NADH redox state using the Fluorometery technique and Tissue Blood Flow (TBF) using the Laser Doppler Flowmetery (LDF) simultaneously and from the same location on each organ (Figure 8) [52-54]. Each channel of this monitoring device contains a bundle of optical fibers for NADH redox state monitoring using the fluorometric technique, and another bundle of fibers for tissue blood flow (TBF) monitoring using Laser Doppler Flowmetry (Fig. 8). The diameter of the probe (including all fibers) is $3 \mathrm{~mm}$. The principle of NADH monitoring from the surface of the tissue ( $1 \mathrm{~mm}$ depth) is that excitation light $(366 \mathrm{~nm})$ passes from the fluorometer to the tissue via a bundle of optical fibers made of quartz. The emitted light (450 nm fluorescence), along with the reflected light ( $366 \mathrm{~nm}$ reflectance), is transmitted to the fluorometer via another bundle of fibers [20]. The emitted light passes through appropriate filters in order to differentiate between $366 \mathrm{~nm}$ reflectance and NADH fluorescence $(450 \mathrm{~nm})$. In addition, a specific filter is used in order to prevent red light (laser Doppler flowmeter) from interfering with mitochondrial NADH monitoring. Changes in the reflected light are correlated to changes in tissue blood volume and therefore serve to correct for hemodynamic artifacts in NADH monitoring [20]. The corrected fluorescence (NADH) is obtained by subtracting the reflectance from the fluorescence signal at a 1:1 ratio. Tissue blood flow was monitored using a laser Doppler flowmeter, based on the Doppler shift reflecting the flow of red blood cells in the microcirculation in a depth of $1-2 \mathrm{~mm}[45,46,55]$. All the signals monitored during the experiment were digitized and transmitted to a multichanneled computerized data acquisition and recording system (Labview A/D software, National Instruments Inc.)

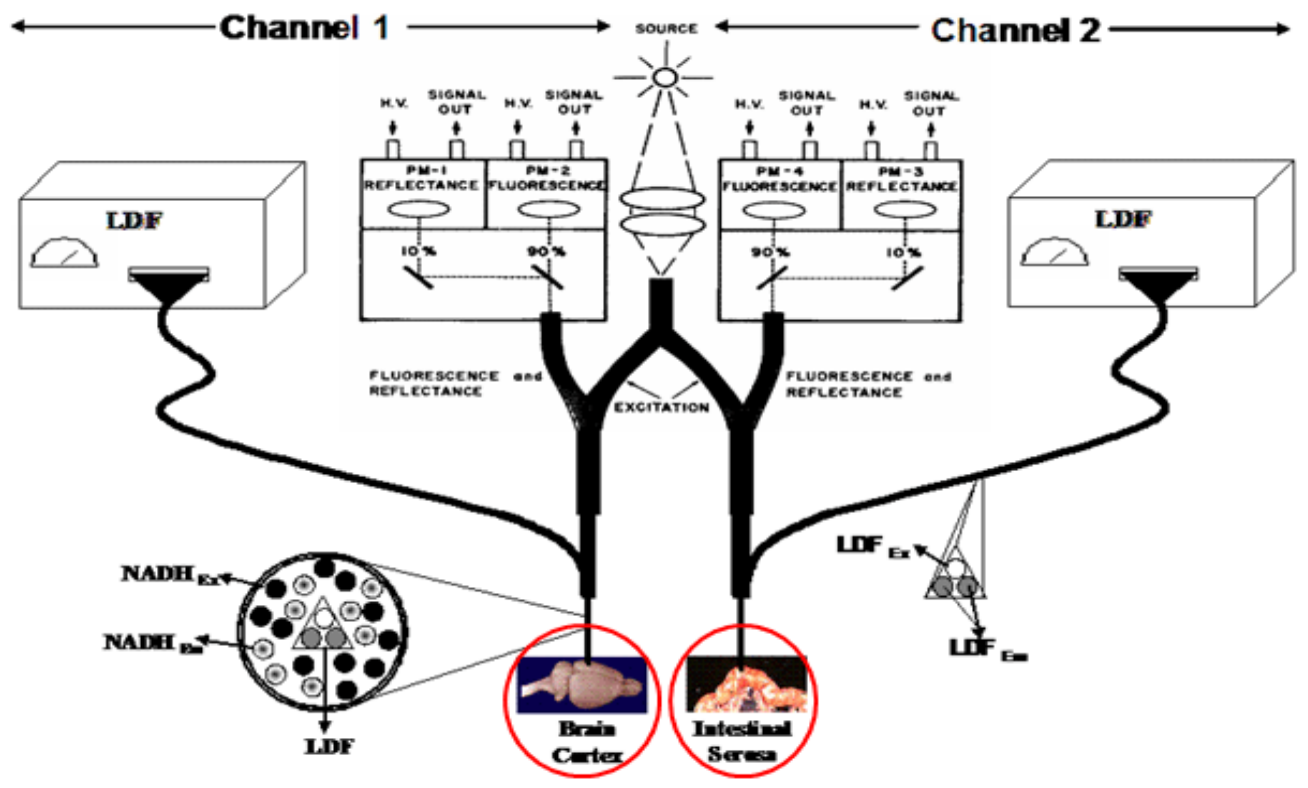

Figure 8: The Multi Site Multi Parametric Monitoring System (MSMP). Schematic presentation of the probe containing optical fibers for NADH monitoring (NADH - mitochondrial NADH redox state, Ex- Excitation, Em- Emission, H.V.- High Voltage ) and for Laser Doppler monitoring (LDF).

All experiments were performed in accordance with the Animal Care Committee of Bar-Ilan University Guidelines. Wister male rats $(220-300 \mathrm{~g})$ were anesthetized by an IP injection of $0.3 \mathrm{ml} / 100 \mathrm{gr}$ of Equithesin (each ml contains: pentobarbital $9.72 \mathrm{mg}$; chloral hydrate $42.51 \mathrm{mg}$; magnesium sulfate 21.25 mg; propylene glycol $44.34 \% \mathrm{w} / \mathrm{v}$; alcohol $11.5 \%$ and water). During the entire experiment, the rats were maintained anesthetized by an addition of $0.1 \mathrm{ml}$ Equithesin every half hour. In addition, a heating pad was placed under the rat to maintain body temperature at $37^{\circ} \mathrm{C}$ and a rectal thermistor probe (Yellow Springs Instruments Co. Inc.) was inserted for body temperature measurements.

Preparation of the brain for monitoring was done by midline incision in the skin, exposing the skull. Then, 3 holes were drilled in the skull. The first hole $(3.5 \mathrm{~mm})$ was drilled on the parietal bone for fixation of a cannula in which a monitoring probe was inserted. The other two holes $(1 \mathrm{~mm})$ were drilled in the frontal bone- distal to the Bregma and from both sides of the central sinus and screws were screwed in for better fixation of the cannula to the skull. Then the whole complex was fixated using dental acrylic cement. The probe was inserted to the cannula and a black cloth was placed around to avoid room light from entering the monitored site and causing artifacts.

For the exposure of the small intestine, an abdominal midline incision below the rib cage was created. Then, a small part of the ileum was exposed and placed above a special plastic holder. Afterwards, the probe was placed on the ileum's serosa using a micromanipulator, with assistance of a small piece of parafilm and cyanoacrylate adhesive. Finally, a slice of parafilm was placed around the probe and over the incision to prevent dehydration 
and a black cloth was placed above to avoid room light from entering the monitored site and causing artifacts.

Figure $9 \mathrm{~A}$ shows the effects of hypoxia $\left(12 \% \mathrm{O}_{2}\right)$ on the brain and intestinal metabolism [54]. The following results were recorded (Fig. 9A): MAP decreased by $34 \pm 4 \mathrm{mmHg}(\mathrm{p}<0.001)$ immediately after the rats started breathing the low-oxygen mixture. This change was followed by a decrease in TBF in the intestine to a level of $56 \pm 13 \%(p<0.05)$ and a tendency of CBF increase to a level of $140 \pm 12 \%$. Simultaneously, the reflectance in the intestine increased $(119 \pm 8 \%, \mathrm{p}<0.05)$, while in the brain it decreased $(92 \pm 2 \%, \mathrm{p}<0.01)$. The changes in the blood supply to the organs produced corresponding changes in the levels of mitochondrial NADH. In the intestine, NADH increased to a level of $151 \pm 14 \%(p<0.01)$ and remained at this level throughout the entire hypoxic period, while in the brain NADH reached a level of $119 \pm 2.8 \%(p<0.001)$. When the rats started breathing air, all the parameters returned to the basal level within $2 \mathrm{~min}$ in the intestine, whereas in the brain hyperemia was observed for 11 minutes, followed by full recovery. With reference to NADH and reflectance, full recovery was observed immediately after the rats started breathing air.

Figure 9B shows the effect of controlled $40 \mathrm{mmHg}$ hypotension, maintained for 60 minutes (Mendelbaum M. et al., unpublished results, 2007). The hypotension was induced by bleeding out $45 \pm 4 \%$ of the rats' total blood volume. During bleeding, MAP sharply decreased by $51 \pm 0.5 \mathrm{mmHg}(\mathrm{p}<0.001)$. Both TBFs decreased rapidly and stabilized at low levels. However, while IBF significantly decreased by $61 \pm 6 \%(\mathrm{p}<0.001)$ CBF significantly decreased only by $45 \pm 5.5 \%(\mathrm{p}<0.01)$. Intestinal reflectance showed a trend of increase, while the cerebral reflectance increased by $5 \pm 2 \%(\mathrm{p}<0.05)$ and decreased back to its basal level. In comparison to the intestinal $\mathrm{NADH}$, which slowly increased up to $228 \pm 24 \%(\mathrm{p}<0.01)$, cerebral NADH increased only to a level of $142 \pm 5 \%(\mathrm{p}<0.01)$. The maximum levels of NADH in both organs were monitored at the end of the hemorrhagic period and were also associated with the maximum changes in TBF.
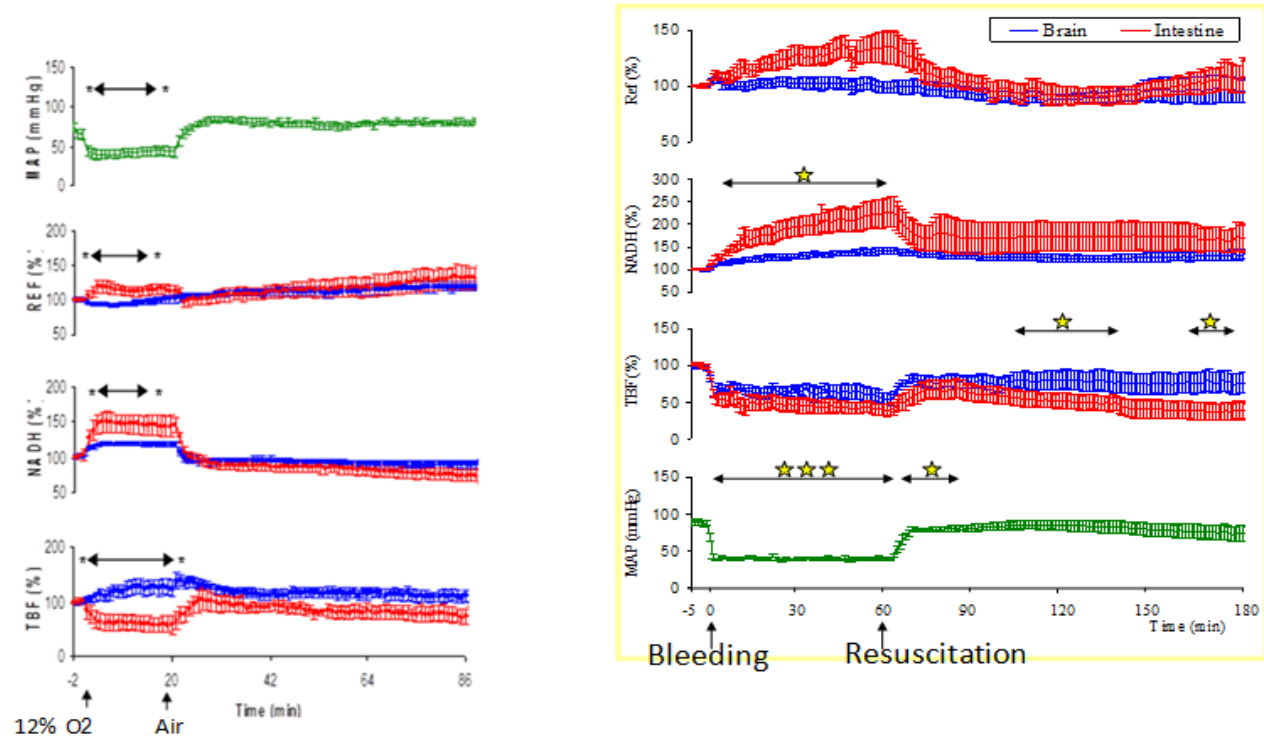

Figure 9A: The responses of brain (blue) and small intestine (red) to hypoxia. Two organs were monitored simultaneously. Arrows show the period of time in which differences between both organs were significant for each minute. (N=9). $\left({ }^{*}\right) \mathrm{p}<0.05$. Ref - reflectance, NADH - mitochondrial NADH redox state, TBF - tissue blood flow, MAP - mean arterial pressure.

Figure 9B:The responses of the brain (blue), small intestine (red) and MAP to controlled hypotension for 60 minutes in a group ( $\mathrm{n}=7$, mean \pm S.E). The arrows represent the period in which significant differences were found between the two organs and the asterisks represent significance levels: ${ }^{*} \mathrm{p}<0.05,{ }^{* *} \mathrm{p}<0.01$ and ${ }^{* * *} \mathrm{p}<0.001$. Asterisks in Ref, NADH and TBF mark significance between brain and intestine; asterisks in MAP mark significance compared to baseline. Ref - reflectance, NADH - mitochondrial NADH redox state, TBF - tissue blood flow, MAP - mean arterial pressure.

Following resuscitation, MAP increased up to basal level. The intestine and the brain responded differently to resuscitation. Intestinal blood flow significantly increased by $30 \pm 9 \%(\mathrm{p}<0.05)$ reaching a level of $69 \%$ followed by a secondary decrease down to $37 \pm 11 \%(\mathrm{p}<0.01)$. Blood flow in the brain increased by $26.5 \pm 8 \%(\mathrm{p}<0.01)$ and stabilized at a level of $82 \%$. The intestinal reflectance decreased sharply below its basal level, followed by an increase back to the basal levels. Cerebral reflectance showed nearly no changes except for a decrease of $12 \pm 5 \%(p<0.05)$ during a short period about an hour after resuscitation. Following resuscitation, NADH in both organs only partially recovered and remained elevated compared to the basal level. When the two organs are compared during bleeding, a significant difference is observed only with respect to NADH levels $(p<0.05)$. Following resuscitation, there were only two episodes of significant differences in the TBF between the organs $(p<0.05)$.

In order to test the involvement of the sympathetic nervous system in the process of blood flow redistribution, the effect of 
the injection of epinephrine on the brain and small intestine. The brain was monitored together with the small intestine serosa layer representing the less vital organ. The response to 2 and 10 micrograms per 100-gram body weight are shown in Figures $10 \mathrm{~A}$ and $\mathrm{B}$, respectively. Catecholamine, such as epinephrine, are released from the adrenal medulla under stress, and contribute to the sympatho-mimetic effect [56], which is characterized by modifying the blood flow distribution, and altering metabolism in order to improve oxygen delivery to vital organs [57]. However, there is no previous study showing the responses of vital versus less-vital organs to epinephrine injection simultaneously in real time.
Figure 10 (Tolmasov $\mathrm{M}$ et al., unpublished) presents the maximum changes in MAP, TBF and $\mathrm{NADH}$ following the injection of each dose of epinephrine in the brain and the intestine. As it is seen, the MAP response showed a dose-dependent character from the dosage of $2 \mu \mathrm{g} / 100 \mathrm{~g}$ BW (part A) to the dosage of $4 \mu \mathrm{g} / 100 \mathrm{~g}$ BW. Namely, the increase from $2 \mu \mathrm{g} / 100 \mathrm{~g}$ BW epinephrine to 4 $\mu \mathrm{g} / 100 \mathrm{~g}$ BW enhanced the response of MAP. However, there was no further increase in MAP, even though the epinephrine dose was raised to 6,8 and $10 \mu \mathrm{g} / 100 \mathrm{~g}$ BW (Fig. 10B).
A
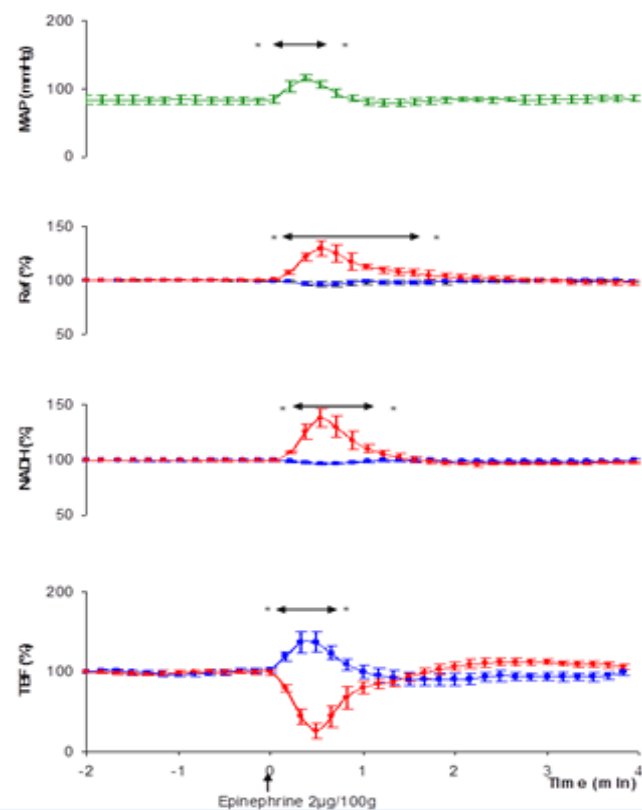

B
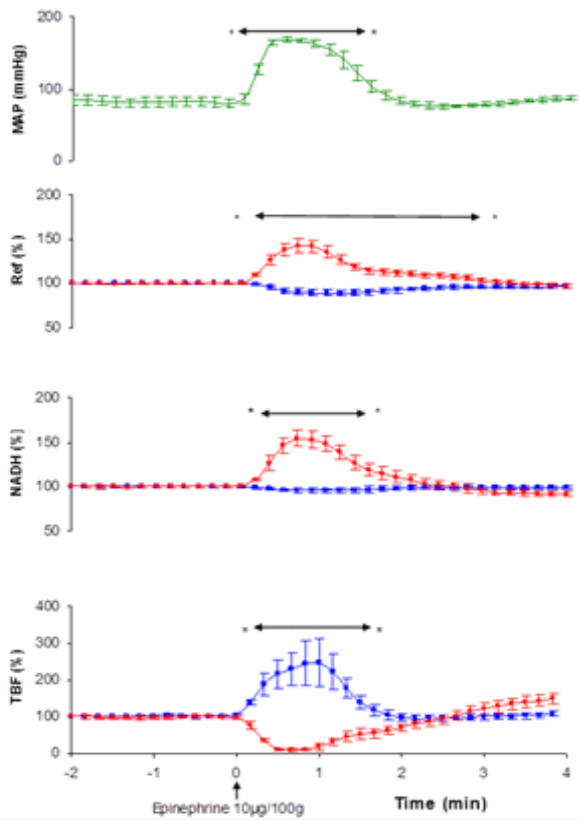

Figure 10A: The responses of the brain (blue) and small intestine (red) to Epinephrine injection (2 $\mu \mathrm{g} / 100 \mathrm{gI.V}$.) Abbreviations are as above. Arrows represent the period of time in which the differences between both organs were significant for each minute. $(\mathrm{N}=9)(*) \mathrm{p}<0.05$.

Figure 10B: The responses of brain (blue) and small intestine (red) to Epinephrine injection (10 $\mu \mathrm{g} / 100 \mathrm{~g}$ I.V.) Abbreviations are as above. Arrows represent the period of time in which the differences between both organs were significant for each minute. $(\mathrm{N}=9)\left({ }^{*}\right) \mathrm{p}<0.05$.

The dose-dependent response pattern at the systemic level was observed also in the response of the blood flow in the brain Namely, the peak of CBF responses to epinephrine at $2 \mu \mathrm{g} / 100 \mathrm{~g}$ $(154 \pm 13 \%, p<0.05)$ was lower than the peak values of CBF after $4 \mu \mathrm{g} / 100 \mathrm{~g}(187 \pm 21 \%, \mathrm{p}<0.05)$ and $6 \mu \mathrm{g} / 100 \mathrm{~g}(215 \pm 32 \%$, $\mathrm{p}<0.05)$. In addition, the maximal response under $4 \mu \mathrm{g} / 100 \mathrm{~g}$ was significantly different when compared to the maximum change induced by $6 \mu \mathrm{g} / 100 \mathrm{~g}$ epinephrine. In contrast to the brain, the intestinal blood flow decreased at the same level under all doses of epinephrine injection.

Consequently, the intestinal NADH responded in the same manner under all doses of epinephrine, whereas in the brain the peak level of NADH after $2 \mu \mathrm{g} / 100 \mathrm{~g}$ epinephrine $(95 \pm 0.5 \%, p<0.05)$ was significantly different when compared to the maximum change that was monitored after $6 \mu \mathrm{g} / 100 \mathrm{gr}$ epinephrine $(90 \pm 1.6 \%, \mathrm{p}<0.05)$.

\section{The CritiView- A New Medical Device for Patient Monitoring}

A new medical device was developed by an Israeli company (CritiSense Ltd) and was cleared by the FDA. The device (Figure $11 \mathrm{~A}$ ) is measuring the same 4 parameters shown in Figure 4 and was tested in animal models $[22,58]$.

The light source unit-LSU (see Figure 11B left side.) of the CRV comprises a $785 \mathrm{~nm} \mathrm{CW}$ laser diode which serves for laser Doppler measurement, a UV LED (375nm) for NADH fluorescence excitation and for total back scatter (or reflection) measurement, a Blue LED (470 nm) and a Green LED (530 nm) for $\mathrm{HbO}_{2}$. In order to enable a very high measurement dynamic range of fluorescence and reflection parameters the light source unit is designed to enable a very wide range of the excitation intensities. To enable this wide excitation range and linearity the system is designed according to a three floors concept (Figure 12 upper left). Each floor comprises three LEDs one UV LED 


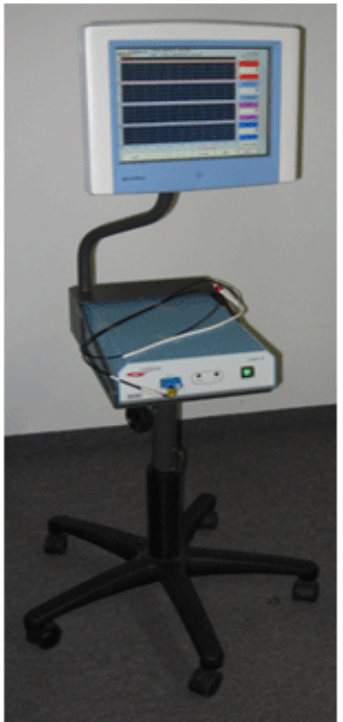

B

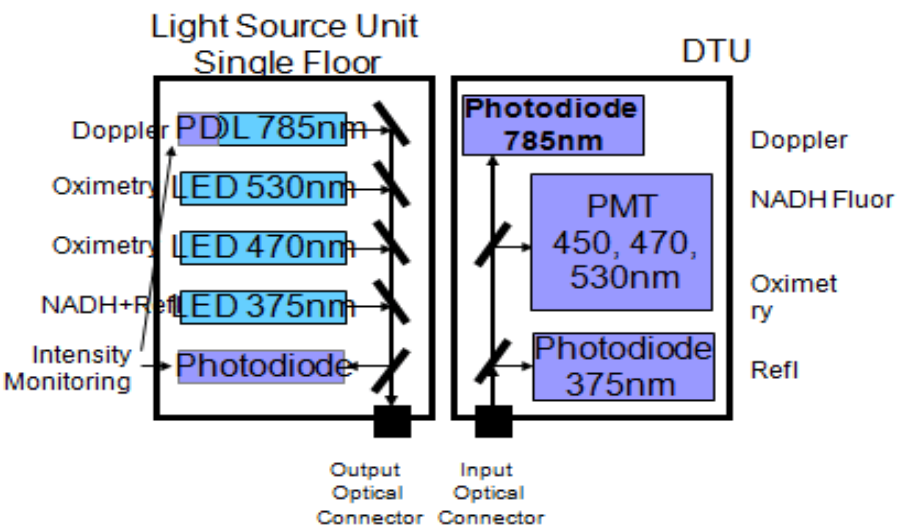

Connector Connector

Figure 11: The basic features of the CritiView developed for experimental and clinical use are presented. The standalone compact device is shown in part A. Detailed schematic description of one of the floors of the CritiView containing the light source unit (LSU) and the detection unit (DTU) appear in part B.

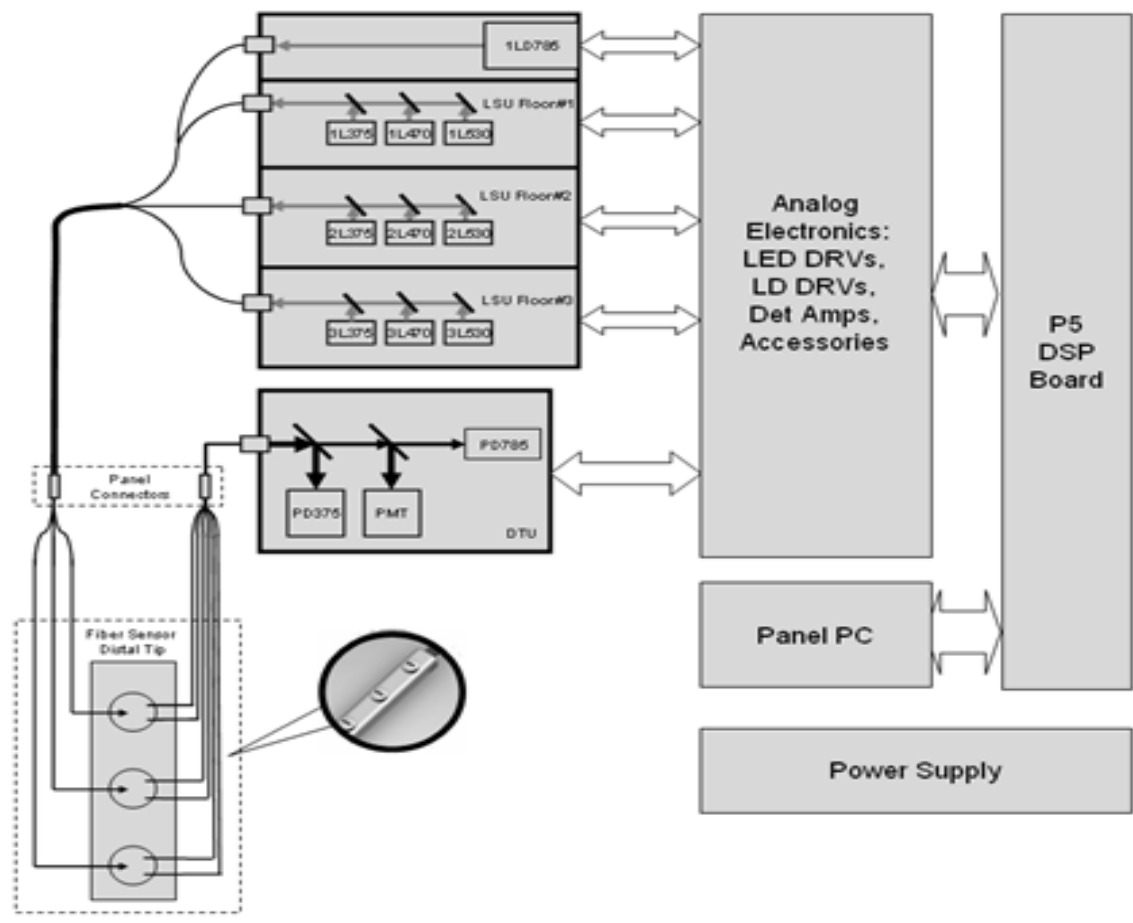

Figure 12: The general parts of the Critiview system are presented.

with emission peak at $375 \mathrm{~nm}$, one Blue LED with emission peak at $470 \mathrm{~nm}$ and one Green LED with emission peak at 530 $\mathrm{nm}$. The different wavelengths from all LEDs of the same floor are assembled together and coupled into a single fiber by a set of dichroic mirrors and appropriate collimation and focusing lenses. The current of each one of the discrete LEDs is set by the appropriate electronics drivers directly controlled by a D/A of the
DSP processor. The difference between the floors is the output intensity. There is a High, Medium and Low intensity floors. The different excitation intensities are achieved by utilizing various pinholes while maintaining all other electro optical properties as the same for all three floors. The light from all three floors and a laser diode is combined into single mixer fiber therefore enabling precise setting of the excitation intensity within a 
very wide excitation range. The near IR laser diode at $785 \mathrm{~nm}$, for laser Doppler measurements, operates in Continuous Wave (CW) operation mode. The UV LEDs, Blue LEDs and Green LEDs operate in chopping mode. This enables usage of synchronous detection techniques in order to detect the NADH fluorescence and total backscatter light. Additionally the chopping operation mode enables one to perform NADH measurements with very low excitation intensities well below the limits specified by the laser safety standards.

The Detection Unit (DTU) All six collection fibers of the fiber optic probe (Figure 12 lower left) are assembled into a single male SC optical connector. The light from the probe passes though the panel connector into a single thick optical fiber that delivers the light to the DTU (Figure 11B). At the DTU entrance the collimation lens collimates the fiber output light. The collimated light is split according to the different wavelengths into the respective photo detectors by means of dichroic beam splitters. The first dichroic beam splitter reflects the total backscatter signal at $375 \mathrm{~nm}$ towards the photodiode detector. The higher wavelengths pass through the first beam splitter towards the second dichroic beam splitter. The second dichroic beam splitter reflects the NADH fluorescence signal at $450 \mathrm{~nm}$ and total backscatter signals at $470 \mathrm{~nm}$ and $530 \mathrm{~nm}$ towards the photomultiplier detector. Due to the chopping operation of the LED's the photomultiplier detector detects each one of the above mentioned signals at different time, i.e., time sharing operation detection mode. The second dichroic filter enables the laser Doppler signal at $785 \mathrm{~nm}$ to pass through it towards the photodiode detector. All acquired signals are digitized into the DSP (digital signal processor) by high resolution 16bit A/D.

The DSP processor (Figure 12) is responsible for whole system control, initial data processing and calculation of Doppler parameter. The DSP is built around Tern Inc. 586-Engine-P controller board with AMD SC520 CPU. After initial data processing the calculated values are transmitted to the panel computer for final data processing display through RS-232 serial interface.

The CRV device utilizes medical grade main power supply for all electronic circuits including the panel computer.

\section{The CRV Optical Probes}

I. The pencil style optical probe has one measurement point to be used on exposed tissue. The excitation and collection fibers are held together in a stainless steel element. It is comprised of one excitation fiber connected to respective excitation connector on the CRV panel; and 6 collection fibers connected to the single collection connector on the CRV front panel.

II. The Foley catheter optical probe for measuring the urethral wall vitality (Figure 14C). It is based upon a standard 3 lumen Foley catheter (The Foley catheter is an inflatable balloon retention type catheter inserted through the urethra, and used to drain the bladder). This probe construction enables the measurement of tissue metabolism at the urethral wall while draining the bladder. The CRV Foley catheter optical probe is designed to perform optical measurements from three adjacent points on the tissue $3.5 \mathrm{~mm}$ apart. Each measurement point is comprised of one excitation fiber and two adjacent collection fibers. The 3 excitation fibers from the LSU are connected to the excitation connector on the CRV panel. All 6 collection fibers from the three measurement points are connected to the single collection connector on the CRV front panel. Figure 14C shows the finished probe.

\section{Testing the CritiView in an Animal Model}

Male rats (250-300 gr) and Mongolian Gerbils (50-75 gr) were used. The animals were anesthetized by Equithesin (Eth = Chloral hydrate $42.51 \mathrm{mg}$; Magnesium sulfate $21.25 \mathrm{mg}$; Alcohol 11.5\%; Propylene glycol 44.34\%; Pentobarbital $9.72 \mathrm{mg}$ ) IP (intraperitoneal) injection of $0.3 \mathrm{ml} / 100$ gram body weight. The animals were kept anesthetized during the operation and during the entire monitoring period, by additional IP injections of E-th $0.03 \mathrm{ml}$ in gerbils and $0.1 \mathrm{ml}$ in rats, every 30 minutes. The addition of small volumes of E-th every 30 minutes kept the animals in a stable state. In the Gerbils, the two common carotid arteries were isolated just before brain surgery and ligatures of 4-0 silk thread were placed around them. The animal was placed in a head holder in the supine position. After a midline incision of the skin, an appropriate hole was drilled in the parietal bone of the right hemisphere. The dura mater remained intact and a light guide holder -cannula was placed in the drilled hole and extra pressure on the tissue was avoided. Two stainless steel screws in the left parietal bone were used to fix the cannula, with dental acrylic cement Body temperature was measured by a rectal probe (YSI) and was regulated to be at the range of $35-37^{\circ} \mathrm{C}$ using a heating blanket.

Metabolic Perturbations Anoxia: Exposure of the animal to oxygen deficient atmosphere by spontaneous breathing of $100 \%$ $\mathrm{N} 2$, for a period of time (approx. $25 \mathrm{sec}$ ) until changes is observed on the monitor, and the animal has stopped breathing. The animal is then allowed to breathe normal room air by spontaneous breathing or by short artificial respiration.

Ischemia: Reversible occlusion $(30 \mathrm{sec})$ of the 2 common carotid arteries by constricting them with threads.

Figure 13 presents the responses of the brain to anoxia and ischemia measured by the CritiView [24]. Actually, the CritiView calculates data on 5 measured signals that are translated into the 4 physiological parameters, namely: TBF, R375, NADH and $\mathrm{HbO}_{2}$. The raw fluorescence signal is translated into the net NADH signal by subtracting the R375 from the Flu signal. The $\mathrm{HbO}_{2}$ signal is obtained by subtracting the R530 (isosbestic reflectance) from the $\mathrm{R} 470$ (the non-isosbestic reflectance). The net reflectance change between the R470 and R530 is reversed in its polarity in order to demonstrate the $\mathrm{HbO}_{2}$ in values of increase or decrease in $\mathrm{HbO}_{2}$ and not the reflectance change. As seen in Figure 13 , under anoxia $(100 \%$ N2) the initial response was the decrease in $\mathrm{HbO}_{2}$ followed by an increase in NADH. The TBF showed a later increase which turned into a hyperemic response that was also recorded in the $\mathrm{HbO}_{2}$ signal after the recovery from anoxia. The responses to complete ischemia induced by bilateral occlusion of the carotid arteries are shown in the right side of figure. Due to the decrease in blood flow and volume to the brain (TBF signal) all measured signals are increasing. The net changes are a large decrease in $\mathrm{HbO}_{2}$ correlated very well to the NADH. A small hyperemia was noticed in the TBF and $\mathrm{HbO}_{2}$ traces. The 


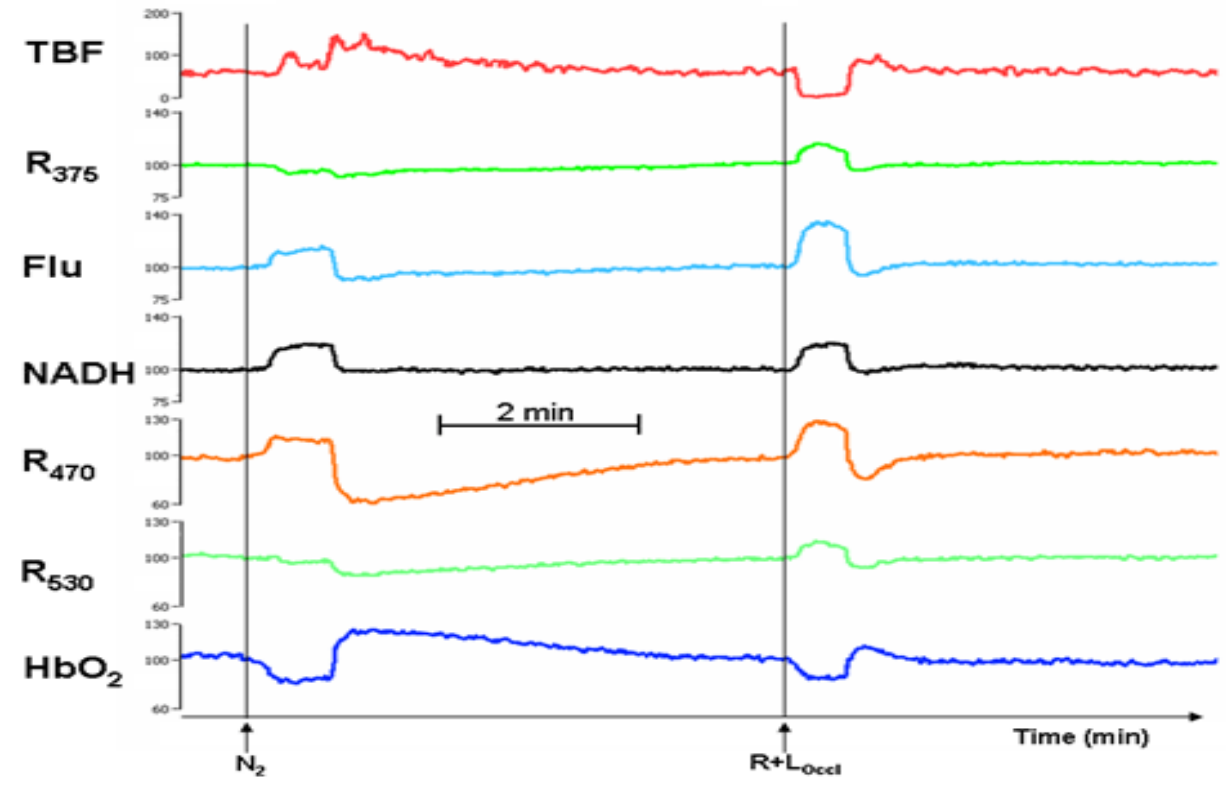

Figure 13: The effects of anoxia (left) and ischemia (right) in part (A) on the 4 parameters measured from the brain of an anesthetized Gerbil using the CritiView. N2 - 100\% Nitrogen,R+Loccl - Occlusion of the right and left common carotid artery, TBF - tissue blood flow, R375 - reflected light at the excitation wavelength of NADH $(375 \mathrm{~nm}), \mathrm{NADH}$ - Corrected fluorescence, $\mathrm{HbO}_{2}$ - Relative levels of hemoglobin oxygenation.
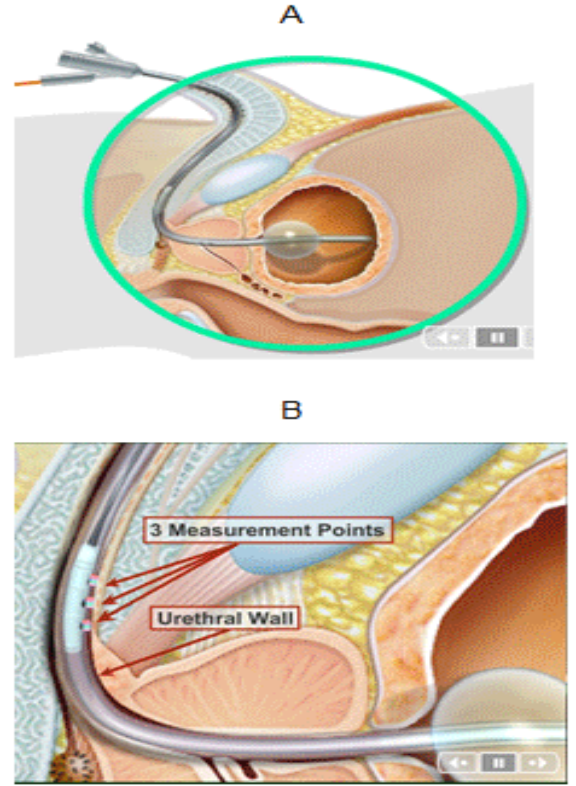

C

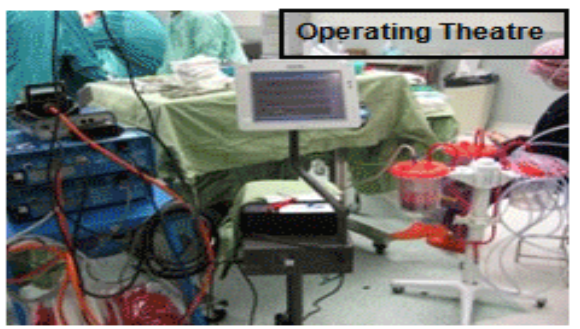

$\mathrm{D}$

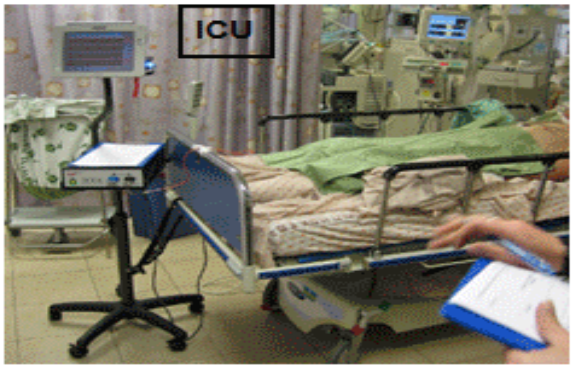

Figure 14: The location of the 3-way Foley catheter and the monitoring sites in the urethral wall (A and B). The CritiView device used for monitoring the urethral wall in the operation room (C) and in the ICU (D).

time needed for recovery to the base line value is much shorter in the NADH signal as compared to the TBF and other reflectance signals (R375, R470, R530).

\section{Testing the CritiView in Patients}

The CritiView device (Fig. 11A) is a low risk device (class 1 laser device) [22]. Figure 14A and B present the positioning of the 3-way Foley catheter (containing the fiber optic sensors) inside the urethra and the bladder of a male patient. The signals from the three points of monitoring are integrated into one value for each of the parameters. The location of the monitoring points in a female patient was adapted to the shorter urethra. Figure 11C and D show the CritiView located in the operating room and in the general ICU respectively.

In a group of five patients we tested the responsiveness of the urethral wall to a clear local event of ischemia achieved 
by the clamping of the abdominal aorta. During this phase of the operation, the microcirculatory blood flow in the urethra decreased in all patients, while the results of NADH measurements showed some variability. Typical responses to aortic occlusion in one of the AAA patients are shown in Figure 15A. The preparation of the aorta for the clamping procedure (marked as P) led to a clear transient decrease in TBF, as well as an increase in the NADH level. The clamping of the aorta led to a maximal decrease in TBF in parallel to the increase in NADH. In this patient, the monitored
$\mathrm{HbO}_{2}$ showed a clear decrease during the clamping interval. Due to a decrease in tissue blood volume, during the aortic occlusion, the reflectance trace showed a large increase until the reopening of the occluded aorta. Immediately after declamping, the initial small increase in TBF led to a fast recovery of the $\mathrm{HbO}_{2}$ and $\mathrm{NADH}$ redox state. All signals recovered to the same values measured during the short control period, although the occlusion interval lasted for more than 80 minutes.

\section{A}
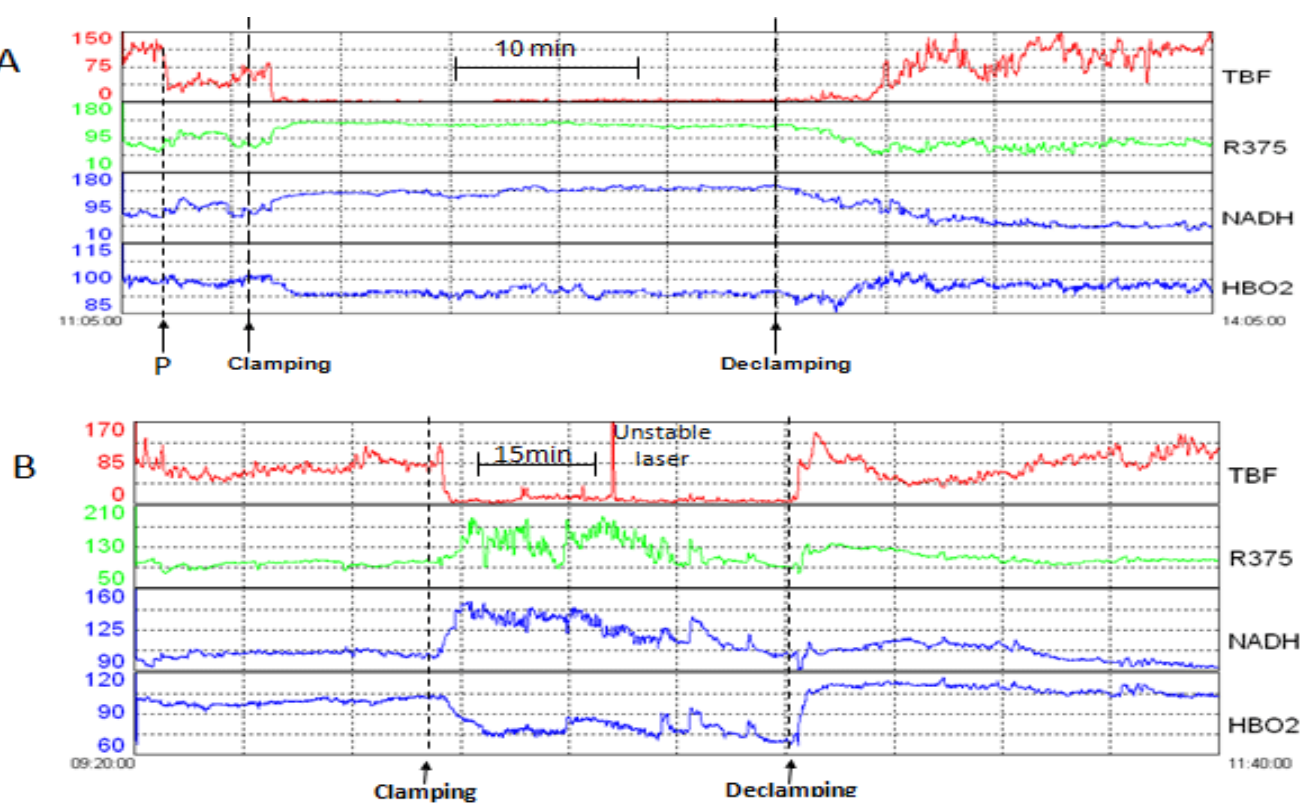

Figure 15: A-Effects of aortic occlusion in a patient that underwent an abdominal aortic aneurysm (AAA) repair operation, on the four parameters monitored by the CritiView. The technical preparation for aortic occlusion was performed a few minutes before the clamping. B- Metabolic and hemodynamic responses (measured in the urethra of a female pig) to complete occlusion of the abdominal aorta.

To reconfirm these findings, we repeated this procedure of aortic clamping in a pig model as seen in Figure 15B [59]. The clamping of the abdominal aorta led to a decrease in the microcirculatory blood flow. During the 50 minutes of the occlusion the TBF was very low but was not a zero level. In parallel to the decrease in TBF, the $\mathrm{HbO}_{2}$ showed a decrease. The response of the NADH could be divided into 2 phases. During the 1 st $40-50 \%$ of the occlusion period a clear increase in the NADH level was recorded. The NADH was deoxidized during the 2nd half of the occlusion period. During the reperfusion period, the $\mathrm{TBF}$ and $\mathrm{HbO}_{2}$ recovered to the original values.

We assumed that under stressful situations the vital organs will maintain their high metabolism on the expense of the less vital organs thus the later ones such as the urethral wall will show decreased perfusion levels and reduced oxygen delivery to the mitochondria. Figures 16 and 17 clearly confirm our assumption.

In Figure 16 three responses of the urethral wall to various manipulations, are presented. In one female patient when spontaneous breathing stopped (Apnea in Fig. 16A) a clear hypoperfusion was recorded in the urethral wall together with a significant increase in NADH levels. As soon as artificial ventilation was restarted, the signals returned to the baseline levels. In another patient, a dramatic decrease in the urethral wall energy state was recorded during a standard airway suction procedure. As Figure 16B shows, a large decrease in the microcirculatory blood flow was measured simultaneously with a marked increase in NADH. These changes suggest that the cardio-respiratory stressful situation induced by suction could be detected by the decrease in the urethral wall vitality. The third patient was monitored during the early post-operative period after coronary artery bypass graft (CABG) operation (Fig. 16C). The left side of the figure shows that, during the initial 3 hours of monitoring, the NADH levels were relatively stable $\_ \pm 20 \%$ change). During the next 40 minutes of monitoring (right side of the figure), a marked mitochondrial dysfunction was recorded $(100 \%$ increase in NADH) in parallel to a decrease in TBF. The NADH response included 2 types of change, namely, a pronounced continuous increase in the NADH levels as well as a number of transient elevations lasting 1-5 minutes each. It was found that, during this period, a cardiac tamponed (accumulation of blood in the pericard) was developed and the patient was returned to the operating room for resternotomy and correcting the blood supply to the heart. The hemodynamic parameters (heart rate and blood pressure), were not clearly correlated to the development of the tamponed. This event proof clearly that monitoring of the urethral wall vitality could serve as an early warning signal for the development of negative oxygen balance in the patient exposed to stressful situation. 


\section{A}
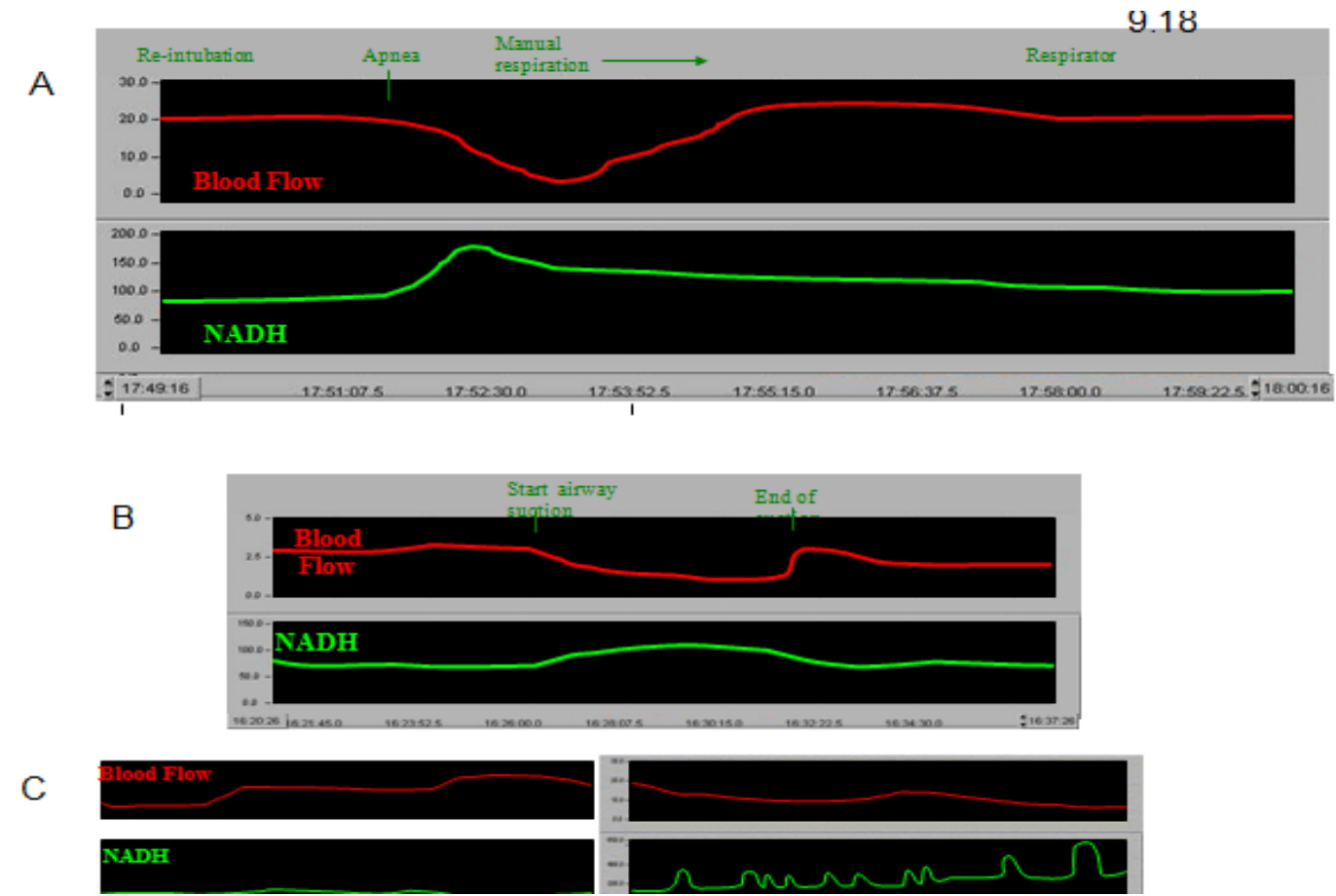

Figure 16: The results of 3 patients monitored in the ICU using an early version of the device named the Tissue Spectroscope. (A) Responses to a cessation of spontaneous respiration in a female patient. (B) Effects of the standard airway suction procedure on the viability of the urethral wall. (C) Monitoring of a patient in the cardiac ICU during the initial 4 hours after the bypass surgery, showing the development of cardiac tamponed.

Three typical responses to the cardiovascular operation procedure are presented in Figure 17. In the first patient shown in Figure 17A, the responses of TBF and NADH were recorded as soon as the preparation for operation started with the scrubbing of the chest area (marked as A).This very early response was found only in one patient monitored in the cardiovascular operation room. The low level of TBF and the high level of NADH were recorded during the entire operation procedure and the recovery began as soon as the chest was closed. When the patient left the operating room for the cardiac ICU, the 2 parameters were close to the baseline levels. These fast responses are probably due to high sensitivity and a fast response of the autonomic nervous system. We could speculate that the level of adrenaline was elevated very early and as a result, the microcirculatory blood flow decreased dramatically and the mitochondrial NADH became highly reduced. In the second patient who underwent the routine CABG operation (Figure 17B) the same type of responses was recorded. TBF reduction and NADH elevation were observed during most of the surgical procedure. Spontaneous transient recovery of TBF and NADH were noted during the second half of the operative procedure. In the third patient operated for aortic repair (Figure 17C), clear responses to the procedure were recorded. In this patient, at 16:49, the initiation of extracorporeal circulation led to a large decrease in TBF and a large increase in NADH. The signals reverted toward the initial values, although not to the baseline levels.

The next step in patient's monitoring device will be to develop a new software tool that will be embedded in the medical device described. The idea is to provide the user of the monitoring device a very easy to use and practical tool that will enable the interpretation of the monitored parameters. A new Tissue Metabolic Score (TMS) will be presented in real time to the user in parallel to the 4 physiological parameters monitored by the device. Figure 18A and B are illustrating the presentation of the TMS on the monitor of the device.

Figure 18C demonstrate the real-time presentation of the TMS together with the main 2 parameters monitored from the urethral wall under cardiovascular surgery. The results presented in Figure 18C were measured in a patient who underwent aortic repair surgery. In the process of opening the chest, a major bleeding occurred and the patient was immediately put on the heart-lung machine and severe hypothermia was induced. As can be seen in part A1 of Figure 18C, while the patient was normothermic, large changes in TBF and NADH were noticed during the major bleeding event. After cooling the patient and shifting him to the heart-lung machine, the signals recovered, although the TBF remained under the control values. While the patient was hypothermic $\left(17^{\circ} \mathrm{C}\right)$, the microcirculatory blood flow was directed mainly to the brain area (Part B1 in Fig. 18C), whereas the TBF to the urethra was decreasing significantly without any clear corresponding change in the NADH levels. This may suggest that the mitochondrial redox state behaves differently under hypothermia. It should be acknowledged that this response was recorded only in one patient. 

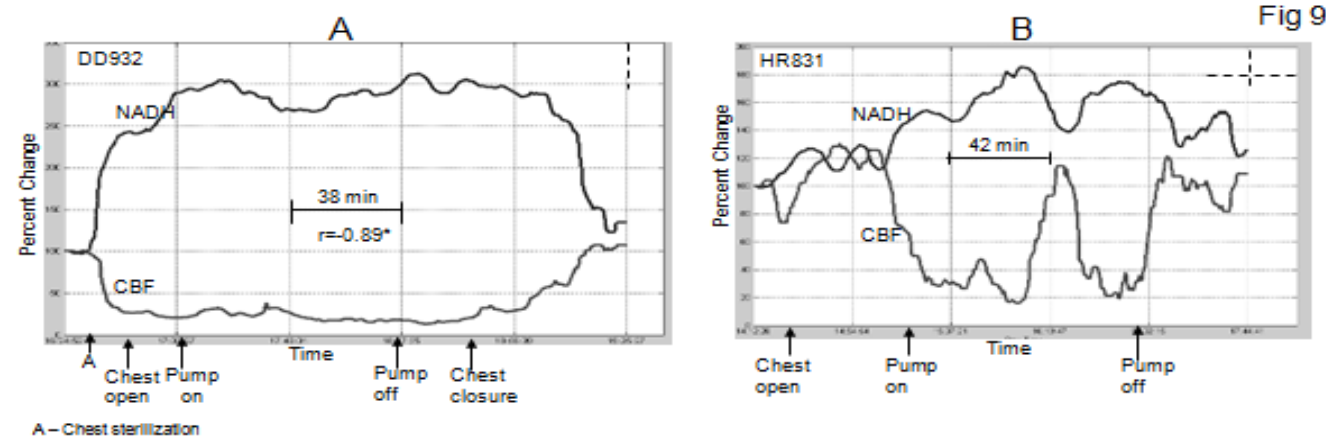

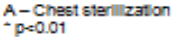

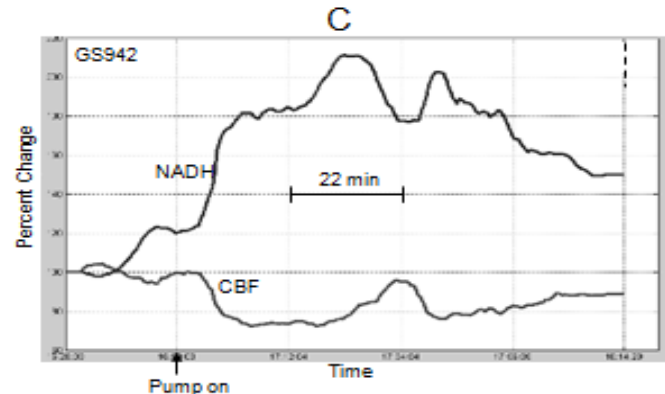

Figure 17: The effects of three surgical procedure, in three cardiovascular operated patients (A, B and C), on the urethral TBF and NADH redox state (see text for detailed explanations).
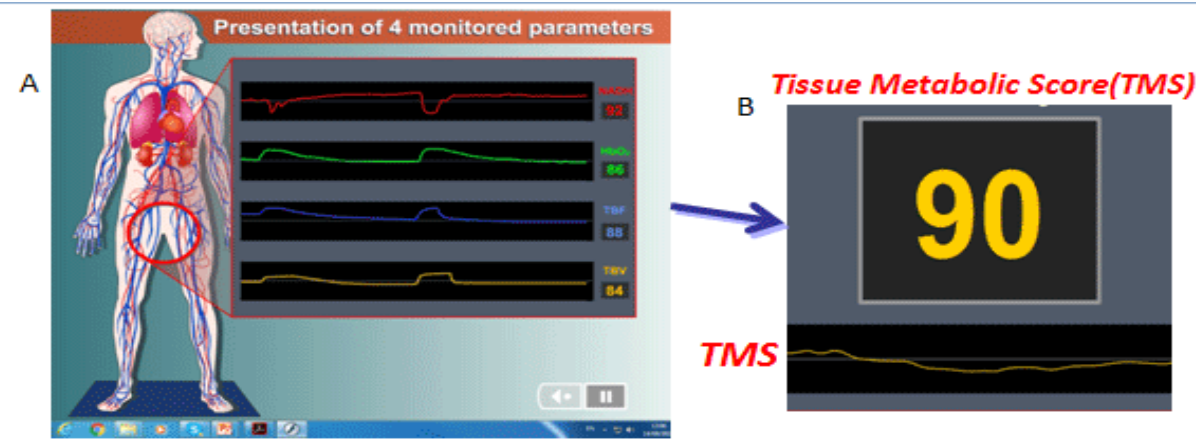

c

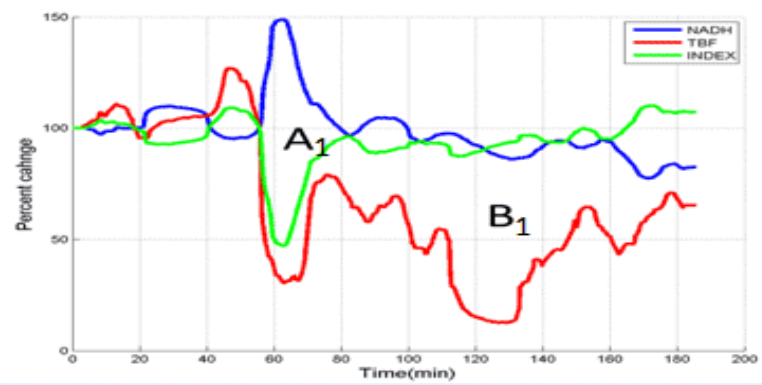

Figure 18: A-Schematic presentation of the four physiological parameters monitored in real time from the urethral wall in critical care patients. BSchematic demonstration of the Tissue Metabolic Score (TMS) calculated from the parameters shown in Part A. C- Responses of the urethral wall TBF and NADH to systemic hypothermia $\left(17^{\circ} \mathrm{C}\right)$ in a patient who underwent the aortic repair operation. (A1) The responses to bleeding under normothermia. $\left(\mathrm{B}_{1}\right)$. The responses to a decrease of microcirculatory blood flow to the lower part of the body. 


\section{Conclusions}

The new approach to monitor patients undergoing cardiovascular surgeries, by the Critiview, was tested successfully under in vitro and animal in vivo experiments as well as in patients. The conclusions from this study are as follows:

1. For the first time mitochondrial NADH, microcirculatory blood flow and oxygenation was measured continuously in the urethral wall of patients.

2. Patients exposed to vascular and open chest surgeries showed changes in the urethral wall measured parameters during the stressful condition of the body.

3. The CritiView results may serve as early warning signals to the deterioration of the body or the end point of resuscitations during and after cardiovascular surgeries.

\section{Disclosure}

Avraham Mayevsky was one of the founders of CritiSense Ltd. that had developed the CritiView device presented in the current manuscript. He was one of the shareholders and served as a director in the BOD. He received consultation fees from the company during the company activity (2004-2007), while serving as chief scientist. The company was closed in 2017.

\section{References}

1. Green D, Paklet L. Latest developments in peri-operative monitoring of the high-risk major surgery patient. Int J Surg. 2010;8(2):90-99. doi: 10.1016/j.ijsu.2009.12.004

2. Roach GW, Kanchuger M, Mangano CM, Newman M, Nussmeier N, Wolman R, et al. Adverse cerebral outcomes after coronary bypass surgery. New Engl J Med. 1996; 335(25):1857-1863.

3. Newman MF, Grocott HP, Mathew JP, White WD, Landolfo K, Reves JG, et al. Report of the substudy assessing the impact of neurocognitive function on quality of life 5 years after cardiac surgery. Stroke. 200132(12): 2874-2881.

4. Hogue CW, Palin CA, Arrowsmith JE. Cardiopulmonary bypass management and neurologic outcomes: An evidence-based appraisal of current practices. Anesth Analg. 2006;103(1):21-37.

5. McKhann GM, Grega MA, Borowicz LM, Baumgartner WA, Selnes OA. Stroke and encephalopathy after cardiac surgery - An update. Stroke. 2006;37(2):562-571.

6. Newman MF, Kirchner JL, Phillips-Bute B, Gaver V, Grocott H, Jones $\mathrm{RH}$, et al. Longitudinal assessment of neurocognitive function after coronary-artery bypass surgery. New Engl J Med. 2001;344(6):395402.

7. Grogan K, Stearns J, Hogue CW. Brain protection in cardiac surgery. Anesthesiol Clin. 2008;26(3):521-538. doi: 10.1016/j. anclin.2008.03.003

8. Edmonds HL. Multi-modality neurophysiologic monitoring for cardiac surgery. Heart Surg Forum. 2002;5(3):225-228.

9. Ekbal NJ, Dyson A, Black C, Singer M. Monitoring tissue perfusion, oxygenation, and metabolism in critically ill patients. Chest. 2013;143(6):1799-1808. doi: 1690427 [pii] 10.1378/chest.12-1849

10. Scheeren TWL. Journal of Clinical Monitoring and Computing 2015 end of year summary: tissue oxygenation and microcirculation. J Clin
Monit Comput. 2016;30(2):141-146. doi: 10.1007/s10877-0169846-4

11. Meirovithz E, Sonn J, Mayevsky A. Effect of hyperbaric oxygenation on brain hemodynamics, hemoglobin oxygenation and mitochondrial NADH. Brain Res Rev. 2007;54(2):294-304.

12. Mayevsky A, Chance B. Intracellular oxidation-reduction state measured in situ by a multicannel fiber-optic surface fluorometer. Science. 1982;217(4559):537-540.

13. Mayevsky A, Rogatsky G. Mitochondrial function in vivo evaluated by NADH fluorescence: From animal models to human studies. Am J Physiol Cell Physiol. 2007;292(2):C615-C640.

14.Chance B, Williams GR. Respiratory enzymes in oxidative phosphorylation (III- The steady state). J Biol Chem. 1955;217(1):409427.

15. Harden A, Young WJ. The influence of phosphates on the fermentation of glucose by yeast-juice: preliminary communication. Proc Chem Soc (London). 1905;21:189-191.

16. Harden A, Young W. Alcoholic ferment of yeast-juice Part II Co-ferment of yeast-juice. Proc Roy Soc. 1906;78(526):369-375.

17. Warburg 0, Christian W, Griese A. Wasserstoff-Ubertragendes Coferment, seine Zusamensetzung und Wirkungsweise. Biochem Zeitschrift. 1935;282:157.

18. Chance B, Cohen P, Jobsis F, Schoener B. Intracellular oxidationreduction states in vivo. Science. 1962;137(3529):499-508.

19. Chance B, Oshino N, Sugano T, Mayevsky A. Basic principles of tissue oxygen determination from mitochondrial signals. Oxygen Transport to Tissue. 1973;37A:277-292.

20. Mayevsky A. Brain NADH redox state monitored in vivo by fiber optic surface fluorometry. Brain Res Rev. 1984;319(1):49-68.

21.Lubbers DW. Optical sensors for clinical monitoring. Acta Anaesth Scand Suppl. 1995;39(104):37-54.

22. Mayevsky A, Walden R, Pewzner E, Deutsch A, Heldenberg E, Lavee J, et al. Mitochondrial function and tissue vitality: bench-to-bedside realtime optical monitoring system. J Biomed Optics. 2011;16(6):067004. doi: $10.1117 / 1.3585674$

23. Kohen E, Kohen C, Thorell B. Use of microfluorimetry to study the metabolism of intact cells. Biomed Eng. 1969:4(12):554-559.

24. Mayevsky A, Barbiro-Michaely E. Shedding light on mitochondrial function by real time monitoring of NADH fluorescence: I. Basic methodology and animal studies. J Clin Monit Comp. 2013;27(1):1-34. doi: 10.1007/s10877-012-9414-5

25. Mayevsky A, Nakache R, Luger-Hamer M, Amran D, Sonn J. Assessment of transplanted kidney vitality by a multiparametric monitoring system. Transplant Proc. 2001;33(6):2933-2934.

26. Mayevsky A, Ornstein E, Meilin S, Razon N, Ouaknine GE. The evaluation of brain CBF and mitochondrial function by a fiber optic tissue spectroscope in neurosurgical patients. Acta Neurochir Suppl. 2002;81:367-371.

27.Sonn J, Mayevsky A. Effects of brain oxygenation on metabolic, hemodynamic, ionic and electrical responses to spreading depression in the rat. Brain Res. 2000;882(1-2):212-216.

28. Mayevsky A, Doron A, Meilin S, Manor T, Ornstein E, Ouaknine GE. Brain viability and function analyzer: multiparametric real-time monitoring in neurosurgical patients. Acta Neurochir Suppl (Wien). 1999;75:63-66. 
29. Rampil IJ, Litt L, Mayevsky A. Correlated, simultaneous, multiplewavelength optical monitoring in vivo of localized cerebrocortical NADH and brain microvessel hemoglobin oxygen saturation. J Clin Monit. 1992;8(3):216-225.

30. Frank KH, Kessler M, Appelbaum K, Dummler W. The Erlangen micro-lightguide spectrophotometer EMPHO I. Phys Med Biol. 1989;34(12):1883-1900. doi: 10.1088/0031-9155/34/12/011

31. Dirnagl U, Kaplan B, Jacewicz M, Pulsinelli W. Continuous measurement of cerebral cortical blood flow by laser-Doppler flowmetry in a rat stroke model. J CBF Metab. 1989;9(5):589-596. doi: 10.1038/ jcbfm.1989.84

32. Haberl RL, Heizer ML, Marmarou A, Ellis EF. Laser-Doppler assessment of brain microcirculation: effect of systemic alterations. Am J Physiol Heart Circ Physiol. 1989;256(4PT2):H1247-1254.

33. Wadhwani KC, Rapoport SI, Shepherd AP, Oberg PA. Blood flow in the central and peripheral nervous systems. In: Shephrd AP, Oberg PA, editors. Laser Doppler Blood Flowmetry Boston: Kluwer Academic Pub. 1990;265-304.

34. Barbiro-Micahely E, Zurovsky Y, Mayevsky A. Real time monitoring of rat liver energy state during ischemia. Microvasc Res. 1998;56(3):253260.

35. Meilin S, Zarchin N, Mayevsky A. Inter-relation between hemodynamic, metabolic, ionic and electrical activities during ischemia and reperfusion in the gerbil brain. Neurol Res. 1999;21(7):699-704.

36. Chance B, Jobsis F. Changes in fluorescence in a frog sartorius muscle following a twitch. Nature. 1959;184:195-196.

37. Chance B. Continuous recording of intracellular reduced pyridine nucleotide changes in skeletal muscle in vivo. Tex Rep Biol Med. 1964;22(1):836-841.

38. Renault G, Raynal E, Sinet M, Muffat-Joly M, Cornillault J, Pocidalo J-J. In situ NADH laser fluorimetry and its application to the study of cardiac metabolism. Adv Exp Med Biol. 1985;191:229-238.

39. Sonn J, Mayevsky A, Acad B, Guggenheimer E, Kedem J. Effect of local ischemia on the myocardial oxygen balance and its response to heart rate elevation. Quart J Exp Physiol. 1982;67(2):335-348.

40. Furman E, Acad B-A, Sonn J, Raul A, Kedem J. Effect of global vs regional ischaemia upon myocardial contractility and oxygen balance. Cardiovasc Res. 1985;19(10):606-612.

41. Osbakken M, Doliba N, Mitchell MD, Ivanics T, Zhang D, Mayevsky A. Acetylcholine: Is it a myocardial metabolic regulator? J Appl Cardiol. 1990;5:357-366.

42. Harken AH, Simson MB, Haselgrove J, Wetstein L, Harden WR, III, Barlow CH. Early ischemia after complete coronary ligation in the rabbit, dog, pig and monkey. Am J Physiol. 1981;241(2):H202-H210.

43. Kedem J, Mayevsky A, Sonn J, Acad B. An experimental approach for evaluation of the 02 balance in local myocardial regions in vivo. Quart J Exp Physiol. 1981;66(4):501-514.

44. Sonn J, Acad B, Mayevsky A, Kedem J. Effect of coronary vasodilation produced by hypopnea upon regional myocardial oxygen balance. Arch Int Physiol Biochim. 1981;89(5):445-455.
45. Osbakken M, Mayevsky A. Multiparameter monitoring and analysis of in vivo ischemic and hypoxic heart. J Basic Clin Physiol Pharmacol. 1996;7(2):97-113.

46. Mayevsky A, Doron A, Manor T, Meilin S, Zarchin N, Ouaknine GE. Cortical spreading depression recorded from the human brain using a multiparametric monitoring system. Brain Res. 1996;740(1-2):268274.

47. Hotchkiss RS, Karl IE. Reevaluation of the role of cellular hypoxia and bioenergetic failure in sepsis. JAMA. 1992;267(11):1503-1510.

48. Marik PE, Varon J. The hemodynamic derangements in sepsis: implications for treatment strategies. Chest. 1998;114(3):854-860.

49. Ince C, Sinaasappel M. Microcirculatory oxygenation and shunting in sepsis and shock. Crit Care Med. 1999;27(7):1369-1377.

50. Meier-Hellmann A, Reinhart K. Effects of catecholamines on regional perfusion and oxygenation in critically ill patients. Acta Anaesthesiol Scand Suppl. 1995;107:239-248.

51.Fullerton JN, Singer M. Organ failure in the ICU: cellular alterations. Semin Respir Crit Care Med. 2011;32(5):581-586. doi: 10.1055/s0031-1287866

52. Mayevsky A. Cerebral blood flow and brain mitochondrial redox state responses to various perturbations in gerbils. Adv Exp Med Biol. 1992;317:707-716.

53.Manor T, Barbiro-Michaely E, Rogatsky G, Mayevsky A. Real-time multi-site multi-parametric monitoring of rat brain subjected to traumatic brain injury. Neurol Res. 2008;30(10):1075-1083. doi: 10.1179/174313208X346107

54.Barbiro-Michaely E, Tolmasov M, Rinkevich-Shop S, Sonn J, Mayevsky A. Can the "brain-sparing effect" be detected in a small-animal model? Med Sci Monit. 2007;13(10):Br211-219.

55. Mayevsky A, Sonn J, Barbiro-Michaely E. Physiological mapping of brain functions in vivo: Surface monitoring of hemodynamic metabolic ionic and electrical activities in real-time. J Neurosci Neuroeng. 2013;2(2):150-177. doi: 10.1166/jnsne.2013.1045

56. Bao G, Metreveli N, Li R, Taylor A, Fletcher EC. Blood pressure response to chronic episodic hypoxia: role of the sympathetic nervous system. J Appl Physiol. 1997;83(1):95-101.

57. Osbakken M, Mayevsky A, Ponomarenko I, Zhang D, Duska C, Chance B. Combined in vivo NADH fluorescence and 31P-NMR to evaluate myocardial oxidative phosphorylation. J Appl Cardiol. 1989;4:305313.

58. Mayevsky A, Dekel N, Oren L, Deutsch A, Pewzner E. Mitochondrial dysfunction: bench-to-bedside optical monitoring of tissue vitality. International Society for Optics and Photonics. 2008;68531B-68511.

59. Mayevsky A, Preisman S, Willenz PE, Castel D, Perel A, Givony D, et al. Evaluation of the CritiView in pig model of abdominal aortic occlusion and graded hemorrhage. International Society for Optics and Photonics. 2009;71730L-71710. 